\title{
Burkholderia cenocepacia differential gene expression during host-pathogen interactions and adaptation to the host environment
}

\section{Eoin P. O'Grady and Pamela A. Sokol *}

Department of Microbiology, Immunology and Infectious Diseases, University of Calgary, Calgary, AB, Canada

\author{
Edited by: \\ Joanna Goldberg, University of \\ Virginia Health System, USA \\ Reviewed by: \\ Leonilde Morais Moreira, Instituto \\ Superior Técnico, Portugal \\ Eshwar Mahenthiralingam, Cardiff \\ University, UK

\section{*Correspondence:} \\ Pamela A. Sokol, Department of \\ Microbiology, Immunology and \\ Infectious Diseases, Faculty of \\ Medicine, University of Calgary, 3330 \\ Hospital Drive NW, Calgary, AB, \\ Canada T2N 4N1. \\ e-mail:psokol@ucalgary.ca
}

\begin{abstract}
Members of the Burkholderia cepacia complex (Bcc) are important in medical, biotechnological, and agricultural disciplines. These bacteria naturally occur in soil and water environments and have adapted to survive in association with plants and animals including humans. All Bcc species are opportunistic pathogens including Burkholderia cenocepacia that causes infections in cystic fibrosis and chronic granulomatous disease patients. The adaptation of $B$. cenocepacia to the host environment was assessed in a rat chronic respiratory infection model and compared to that of high cell-density in vitro grown cultures using transcriptomics. The distribution of genes differentially expressed on chromosomes 1,2 , and 3 was relatively proportional to the size of each genomic element, whereas the proportion of plasmid-encoded genes differentially expressed was much higher relative to its size and most genes were induced in vivo. The majority of genes encoding known virulence factors, components of types II and III secretion systems and chromosome 2-encoded type IV secretion system were similarly expressed between in vitro and in vivo environments. Lower expression in vivo was detected for genes encoding $\mathrm{N}$-acylhomoserine lactone synthase Cepl, orphan LuxR homolog CepR2, zinc metalloproteases ZmpA and ZmpB, LysR-type transcriptional regulator ShvR, nematocidal protein AidA, and genes associated with flagellar motility, Flp type pilus formation, and type VI secretion. Plasmid-encoded type IV secretion genes were markedly induced in vivo. Additional genes induced in vivo included genes predicted to be involved in osmotic stress adaptation or intracellular survival, metal ion, and nutrient transport, as well as those encoding outer membrane proteins. Genes identified in this study are potentially important for virulence during host-pathogen interactions and may be associated with survival and adaptation to the host environment during chronic lung infections.
\end{abstract}

Keywords: Burkholderia cenocepacia, Burkholderia cepacia complex, microarray, lung infection, rat chronic respiratory infection model, in vitro, in vivo

\section{INTRODUCTION}

Members of the Burkholderia cepacia complex (Bcc) are commonly found in soil and aquatic environments (LiPuma, 2010; Loutet and Valvano, 2010). Seventeen Bcc species have been identified, all of which have the potential to be opportunistic pathogens, although Burkholderia cenocepacia is the most clinically significant. B. cenocepacia causes lung infections resulting in significantly decreased survival rates in cystic fibrosis and chronic granulomatous disease patients (Mahenthiralingam et al., 2005). The organism is intrinsically multidrug resistant and can persist in the lungs of CF patients for many years (Mahenthiralingam et al., 2008). In some patients, infection with B. cenocepacia can progress to what is termed "cepacia syndrome." Cepacia syndrome is associated with a rapid deterioration in lung function associated with necrotizing pneumonia, bacteremia and sepsis that can result in death (Isles et al., 1984).

Many virulence factors have been identified in B. cenocepacia including extracellular enzymes, toxins, secretions systems, iron acquisition systems, cell-cell communication (quorum sensing, QS) systems, regulatory proteins as well as genes contributing to motility, biofilm formation, adhesion, cell invasion, intracellular survival, and bacterial protection from host factors (for review see Loutet and Valvano, 2010). Several infection models have been employed to identify and characterize the contribution of numerous genes to pathogenesis (Uehlinger et al., 2009). B. cenocepacia exhibits virulence against Caenorhabditis elegans (Kothe et al., 2003), Galleria mellonella (Seed and Dennis, 2008), Acanthamoeba (Marolda et al., 1999), Dictyostelium discoideum (Aubert et al., 2008), Danio rerio (Vergunst et al., 2010), Drosophila melanogaster (Castonguay-Vanier et al., 2010), and alfalfa seedlings (Bernier et al., 2003). Chronic respiratory infection models have been developed in mice and rats to investigate pathogenesis of Bcc species. The rat chronic respiratory infection model described by Cash et al. (1979) involves transtracheal delivery of agar-embedded bacteria directly into the lung allowing for bacterial persistence and pathology to be measured. 
This chronic infection model has been used to identify Bcc species and bacterial strains that persisted or caused lung pathology from less virulent strains such as mutants in ornibactin biosynthesis, uptake and utilization, zinc metalloproteases, and genes encoding other enzymes, transcriptional regulators, and lipopolysaccharide (Sokol et al., 1999, 2000; Bernier et al., 2003, 2008; Corbett et al., 2003; Baldwin et al., 2004; Bernier and Sokol, 2005; Kooi et al., 2006; Loutet et al., 2006; Flannagan et al., 2007). These studies have revealed the importance of individual genes or systems to virulence but have not assessed bacterial gene expression during infection.

Transcriptional profiling using custom B. cenocepacia microarrays and RNA sequencing technology have enabled in vitro gene expression studies to be performed at a genome level. Transcriptional profiling has been used to examine gene expression in different environmental conditions such as those mimicking CF sputum or soil, or in response to antimicrobials (Drevinek et al., 2008; Yoder-Himes et al., 2009, 2010; Peeters et al., 2010; Bazzini et al., 2011; Coenye et al., 2011; Sass et al., 2011). In addition to further characterizing genes previously known to be important in virulence, these studies have also identified many genes with potential importance in virulence. Our current understanding of $B$. cenocepacia physiology, pathogenesis, and survival is incomplete since the B. cenocepacia genome, which is over $8 \mathrm{Mb}$, contains genes encoding many uncharacterized proteins. Identifying such proteins and determining their functional significance will improve our abilities to target such proteins for therapeutic purposes. To date, no studies have profiled B. cenocepacia gene expression at the whole genome level directly from infected cells/tissues or during infection of a susceptible host. To further understand B. cenocepacia adaptation to the host environment, we have used microarrays to examine the B. cenocepacia gene expression signature in the rat chronic respiratory infection model and compared this to high cell-density laboratory-grown cultures.

\section{MATERIALS AND METHODS \\ BACTERIAL STRAINS AND GROWTH CONDITIONS FOR IN VITRO SAMPLES}

Burkholderia cenocepacia K56-2 is a CF isolate that belongs to the ET12 lineage (RAPD type 2) and is clonally related to the sequenced strain J2315 (Mahenthiralingam et al., 2000; Baldwin et al., 2004; Holden et al., 2009). To generate in vitro samples, K56-2 cultures were grown at $37^{\circ} \mathrm{C}$, in $10 \mathrm{ml}$ Miller's Luria broth (LB; Invitrogen, Burlington, ON, Canada) with shaking in $125 \mathrm{ml}$ Erlenmeyer flasks to stationary phase $(16 \mathrm{~h})$ as previously described (O'Grady et al., 2009). Bacterial growth was assessed by determining the optical density (OD) at $600 \mathrm{~nm}$.

\section{ANIMAL STUDIES}

Animal infections were performed using the rat agar bead respiratory infection model (Cash et al., 1979). Adult male SpragueDawley rats (150-180 g; Charles River, QC, Canada) were inoculated transtracheally with approximately $10^{7} \mathrm{CFU}$ of K56-2. At 3 days postinfection, infected lungs were aseptically removed, stored at $4^{\circ} \mathrm{C}$ overnight in $15 \mathrm{ml}$ of RNA later (Ambion, Streetsville, $\mathrm{ON}$, Canada), and subsequently maintained at $-70^{\circ} \mathrm{C}$ to prevent
RNA degradation. Animal experiments were conducted according to the guidelines of the Canadian Council of Animal Care for the care and use of experimental animals under protocol M08089 approved by the University of Calgary Animal Care Committee.

\section{RNA MANIPULATIONS}

Total RNA from in vitro samples was prepared as previously described (O'Grady et al., 2009) using a RiboPure bacterial RNA isolation kit according to manufacturer's instructions (Ambion). For in vivo samples, total RNA from infected lungs was isolated using Tri Reagent (Invitrogen) as recommended by the manufacturer. Total RNA samples were enriched for bacterial RNA using a MicrobEnrich kit (Ambion) and purified using a MegaClear kit (Ambion). Enriched and purified bacterial RNA was depleted of $16 \mathrm{~S}$ and $23 \mathrm{~S}$ rRNAs using a MicrobExpress kit (Ambion) to isolate mRNA according to manufacturer's instructions to provide enhanced sensitivity for microarray experiments. DNase treatment was performed on all RNA samples using DNA-Free (Ambion), and samples were confirmed by PCR using Taq polymerase (Invitrogen) to be free of DNA prior to cDNA synthesis.

\section{MICROARRAY ANALYSIS}

In vitro-derived total RNA and in vivo-derived mRNA samples were indirectly labeled with the CyScribe Post-Labelling Kit (GE Healthcare) and cDNA synthesis performed as described by Sass et al. (2011) with the following modifications. Three independent RNA samples were used for in vitro samples and two mRNA samples (each consisting of an mRNA pool isolated from two infected rats to reduce variability between animals) were used for in vivo samples. Approximately $10 \mu \mathrm{g}$ total RNA was labeled for each in vitro sample and $8 \mu \mathrm{g}$ mRNA was labeled for each in vivo sample. The reference pool for microarray experiments consisted of B. cenocepacia J2315 genomic DNA isolated and labeled as described (Sass et al., 2011). The B. cenocepacia J2315 custom microarray, with each probe printed four times using the Agilent Sure Print $4 \times 44$ microarray platform, was used (Drevinek et al., 2008; Sass et al., 2011). Approximately 700-1000 ng labeled cDNA from the in vitro and in vivo samples and $55 \mathrm{ng}$ labeled control genomic DNA was used per microarray. Hybridization, washing, and scanning were performed as described using the Two Color Microarray Based Gene Expression Analysis Protocol (Agilent) and the data analyzed using GeneSpring GX version 7.3.1. All labeling, hybridization, and scanning were performed by the Mahenthiralingam Laboratory, Cardiff University, Wales. Initial data were preprocessed by employing the enhanced Agilent FE import method. Probes specific to J2315 were filtered on a 1.5fold change in expression between conditions to identify clusters of differentially regulated genes related to specific functions or potentially organized in operons. To eliminate potential differences in RNA between samples, data were normalized to control samples and mean $\log _{2}$ ratios (in vivo/in vitro) calculated from replicates were used and reported as expression ratios. Mean $\log _{2}$ ratios were also filtered on twofold changes in expression between in vivo and in vitro conditions to identify more stringently differentially regulated genes. The in vitro- or in vivo-derived K56-2 
cDNA produced a signal that was detected by at least $94 \%$ of the probes on the microarray. Operon prediction and gene annotation or predicted protein function were retrieved from the $B$. cenocepacia J2315 genome at http://www.burkholderia.com (Winsor et al., 2008) or http://www.microbesonline.org (Dehal et al., 2009). The entire microarray data set has been deposited in the Array Express database http://www.ebi.ac.uk/arrayexpress under accession number E-MEXP-3367.

\section{OUANTITATIVE RT-PCR}

RNA for quantitative RT-PCR (qRT-PCR) was derived independently of that used for microarray analysis. Briefly, total RNA was isolated from three independent in vitro cultures prepared as described above. In a separate animal experiment to that used to prepare the microarray samples, enriched and purified total RNA was isolated as described above from three infected rats yielding three independent in vivo samples. Oligonucleotide primers (Table 1) were designed with Primer3 (Rozen and Skaletsky, 2000) and were synthesized by the University of Calgary Core DNA Services (Calgary, AB, Canada). BCAL0421 (gyrB) encoding DNA gyrase subunit B, previously used as a housekeeping gene in the Bcc multilocus sequence typing scheme (Baldwin et al., 2005) was used as a control as described previously (Peeters et al., 2010). Expression of $g y r B$ was not significantly altered according to microarray analysis (data not shown). RT-PCR was performed using an iScript Select cDNA synthesis kit (Bio-Rad, Mississauga, ON, Canada). Quantification and melting curve analyses were performed with SsoFast Evagreen supermix with low ROX on an iCycler (Bio-Rad) according to manufacturer's instructions. For each of the three in vitro and in vivo cDNA samples, qRT-PCRs were performed in triplicate, normalized to the control gene, gyrB. Data were calculated as previously described (Schmittgen and Livak, 2008) and represented as fold change of the in vivo samples relative to the in vitro samples.

\section{RESULTS}

\section{GENES ON ALL GENOMIC ELEMENTS ARE INDUCED IN RESPONSE TO} THE HOST ENVIRONMENT

Global gene expression profiles were generated using microarrays from $B$. cenocepacia cultures recovered from rat lungs 3 days postinfection using a chronic respiratory infection model and compared to those of B. cenocepacia cultures grown to high celldensity in vitro. Using a fold change cut off of $\geq 1.5$, we identified 366 genes that were induced in vitro and 304 genes that were induced in vivo (Table 2). The B. cenocepacia J2315 genome is comprised of four genetic elements: chromosome 1, $3.87 \mathrm{Mb}$; chromosome 2, 3.22 Mb; chromosome 3, $0.88 \mathrm{Mb}$; and a plasmid, $0.09 \mathrm{Mb}$ (Holden et al., 2009). Differential expression was observed for genes present on the three chromosomes as well as the plasmid. The number of genes induced in vitro or induced in vivo on each genomic element and the percentage of the total number of genes induced in vitro or in vivo located on each genomic element is shown in Table 2. For in vitro induced genes, the distribution of changes across the genome was relatively proportional to the size of each genomic element, i.e., a decreasing percentage of genes showed altered expression from chromosomes 1 through 3 and to the plasmid. Interestingly, more than $20 \%$ of genes induced in vivo were plasmid genes indicating this group of genes was highly overrepresented (Table 2). Consistent with this observation, for chromosomes 1 through 3, the percentage of genes on each replicon induced in vivo was similar and ranged from 2.9 to $4.8 \%$, in marked contrast to the plasmid where $66 \%$ of plasmid-encoded genes were induced in vivo (Table 2).

\section{A MAJORITY OF CHARACTERIZED VIRULENCE GENES ARE SIMILARLY EXPRESSED BETWEEN IN VITRO AND IN VIVO ENVIRONMENTS}

At least 28 genes have been characterized in B. cenocepacia that are known to be important for virulence and belong to functional groups including stress resistance, extracellular enzymes or

Table 1 | Oligonucleotide primers used in this study for qRT-PCR.

\begin{tabular}{|c|c|c|c|}
\hline Primer & Sequence $\left(5^{\prime}-3^{\prime}\right)$ & Product size (bp) & Reference \\
\hline L0114fliCRTfor1 & GCGTGTCGATGATTCAAACGGCAT & \multirow[t]{2}{*}{159} & \multirow[t]{2}{*}{ O'Grady et al. (2009) } \\
\hline L0114fliCRTrev1 & TCACTTCCTGGATCTGCTGCGAAA & & \\
\hline L0343hcpRTrev1 & CGCGTAGGTCTTGTCGTTCT & 120 & This study \\
\hline L1525qRTfor1 & AGCAATCATCAAGCGTTTCC & 87 & This study \\
\hline M2194mmsAqRTrev1 & TCGATCTCGCTCTGGAACTT & 164 & This study \\
\hline M2702prpCqRTfor1 & GAAATCCAGAGCCGCTACAG & \multirow[t]{2}{*}{83} & \multirow[t]{2}{*}{ This study } \\
\hline M2702prpCqRTrev1 & CCGATCACCACTTCCTTGTT & & \\
\hline pBCA025traFqRTfor 1 & TCGACCTTTGCTGATACGTG & \multirow[t]{2}{*}{196} & \multirow[t]{2}{*}{ This study } \\
\hline pBCA025traFqRTrev1 & GGCAGTAAGGGCAGTCAGAG & & \\
\hline L0421gyrBqRTfor1 & GTTCCACTGCATCGCGACTT & 109 & Peeters et al. (2010) \\
\hline L0421gyrBqRTrev1 & GGGCTTCGTCGAATTCATCA & & \\
\hline
\end{tabular}


Table 2 | Microarray analysis of B. cenocepacia genes induced in vitro or induced in vivo.

\begin{tabular}{|c|c|c|c|c|c|}
\hline & \multicolumn{4}{|c|}{ Genomic element } & Total \\
\hline Number of genes induced in vivo & 104 & 102 & 36 & 62 & 304 \\
\hline Percentage of total genes induced in vitro (\%) & $49.7^{\mathrm{c}}$ & 38.0 & 12.0 & 0.3 & 100 \\
\hline Percentage of total genes induced in vivo (\%) & 34.2 & 33.6 & 11.8 & 20.4 & 100 \\
\hline Percentage of genes on each replicon induced in vivo (\%) & 2.9 & 3.6 & 4.8 & 66.0 & 4.2 \\
\hline
\end{tabular}

${ }^{a}$ Chr, chromosomes 1, 2, or 3 of B. cenocepacia J2315.

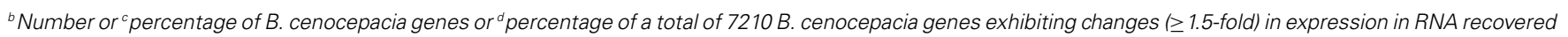
from rat lungs (in vivo) relative to RNA isolated from in vitro grown cultures as determined by microarray analysis.

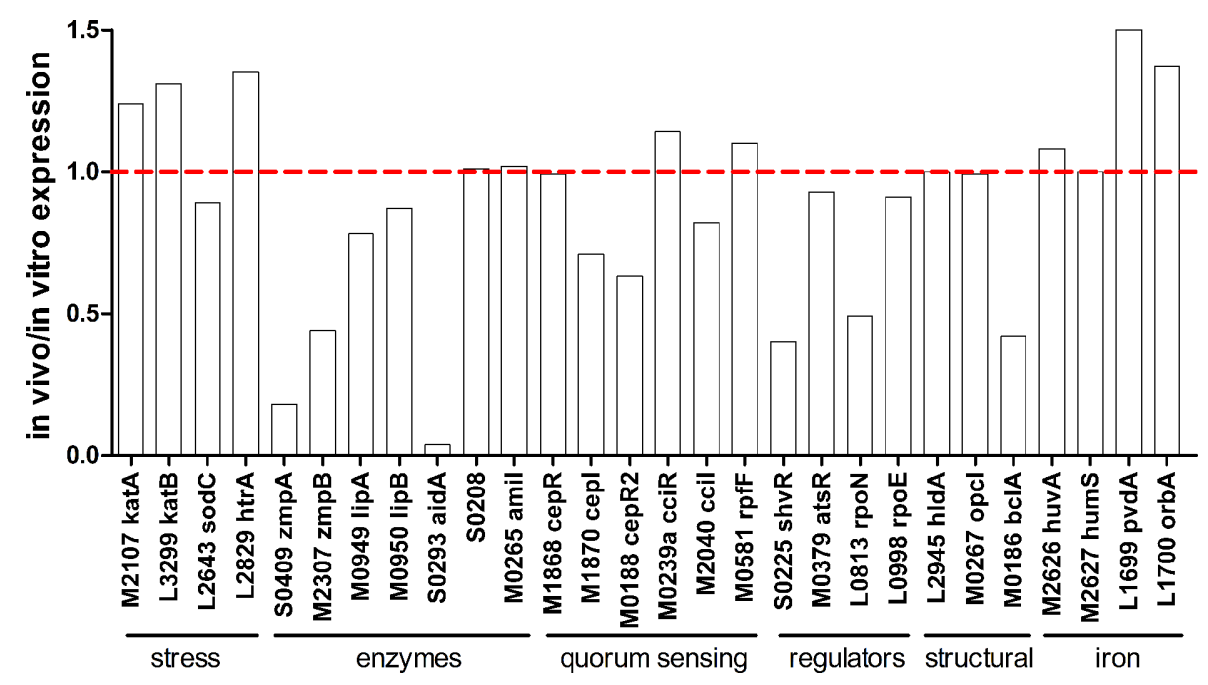

FIGURE 1 | In vivo expression of characterized virulence genes. Expression ratio of RNA recovered from rat lungs (in vivo) relative to RNA isolated from in vitro grown cultures as determined by microarray analysis. The "BCA" designation has been removed from names of genes encoded on chromosomes 1,2 , and 3 for image clarity.

secreted toxins, QS, transcriptional regulation, as well as genes involved in heme uptake, iron acquisition, and the synthesis of structural components such as lipopolysaccharide, porins, and lectins (Loutet and Valvano, 2010). Analysis of these virulence genes showed that expression of the majority of these genes was similar between in vitro and in vivo conditions (Figure 1). The expression of cepI, encoding an $N$-acyl-homoserine lactone (AHL) synthase, was somewhat lower in vivo and this observation was consistent with lower expression of CepIR-regulated genes including those encoding extracellular zinc metalloproteases $\mathrm{ZmpA}$ and ZmpB, the orphan LuxR homolog CepR2 and the LysR-type transcriptional regulator ShvR (Figure 1). Two other genes known to be influenced by CepIR such as the major catalase/peroxidase encoded by $k a t B$ and an acyl-CoA dehydrogenase encoded by BCAS0208 were similarly expressed in the in vitro and in vivo environments (Figure 1). The BCAS0208 mutant caused less lung pathology than wild type in the rat chronic respiratory infection model (Subramoni et al., 2011).
Limited iron availability in mammals is circumvented by infectious pathogens by the production of iron binding and transport complexes such as heme binding proteins and siderophores. Although genes involved in heme transport ( $h u v A$ and $h m u S$ ) were not differentially expressed between in vivo and in vitro environments (Figure 1), huvA mutants exhibited survival defects in the rat chronic respiratory infection model (Hunt et al., 2004). Genes involved in ornibactin biosynthesis and transport were also expressed at similar levels in both environments, although ornibactin mediated iron uptake is required for persistence in the rat chronic respiratory infection model (Visser et al., 2004). Among the characterized virulence genes, the lowest in vivo expression ratio (0.04) was observed for BCAS0293 (aidA; Figure 1). The aidA gene encodes a protein that significantly contributes to virulence against $C$. elegans (Huber et al., 2004), but an aidA mutation had no effect on virulence in the rat chronic respiratory infection model (Uehlinger et al., 2009). 


\section{SECRETION SYSTEMS ARE SELECTIVELY REGULATED BETWEEN IN VITRO AND IN VIVO ENVIRONMENTS}

Burkholderia cenocepacia has one type II, type III, and type VI protein secretion systems (T2SS, T3SS, and T6SS, respectively) that contribute to pathogenesis, and two type IV secretion systems (T4SS), one of which has been shown to be important in virulence. Expression of genes encoding components of each of these systems varied between in vitro and in vivo environments.

The T2SS is composed at least 12 ORFs on three gsp operons and is involved in secretion of extracellular zinc metalloproteases $\mathrm{ZmpA}, \mathrm{ZmpB}$, and other extracellular proteins that have enzymatic activity such as phospholipase $\mathrm{C}$, hemolysin, lipase, and polygalacturonase (Fehlner-Gardiner et al., 2002; Kothe et al., 2003; Gingues et al., 2005; Somvanshi et al., 2010). Expression of the three gsp operons encoding the T2SS was similar between in vitro and in vivo conditions (Figure 2A). Apart from the lower expression of $z m p A$ and $z m p B$ in vivo (Figure 1), expression of other genes encoding enzymes secreted by the T2SS described above was not different between in vitro and in vivo conditions (data not shown). The B. cenocepacia T3SS genes are organized in two operons on chromosome 2 thought to be responsible for secretion of effector proteins that have yet to be identified (Tomich et al., 2003; Glendinning et al., 2004). Mutation of $b c s c N$, encoding an ATPbinding protein, reduced bacterial survival, and lung inflammation in a mouse agar bead infection model (Tomich et al., 2003). In our study, the mean expression ratio of genes in the $b c s c Q$ and $b c s c V$ operons was 1.03 and 0.99 , respectively, in the in vivo compared to in vitro conditions (Figure 2B) indicating that there was no difference in expression.

Two gene clusters located on chromosome 2 and the plasmid have been identified to encode components of T4SS. Interestingly, the plasmid-encoded T4SS was induced in vivo. The bc-VirB/D4 T4SS on chromosome 2 shares homology with the Agrobacterium tumefaciens T4SS and is involved in plasmid mobilization
A

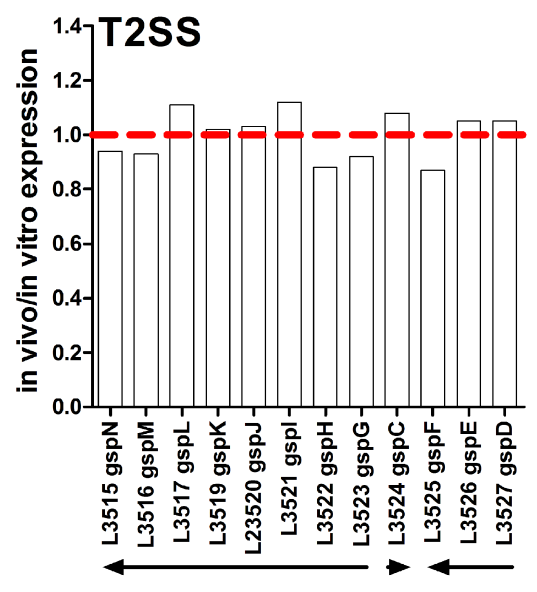

C

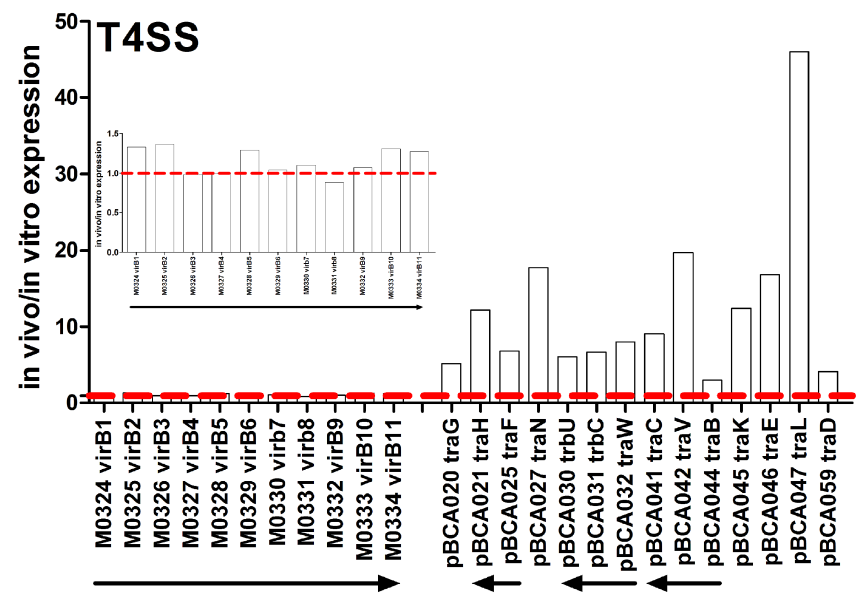

B

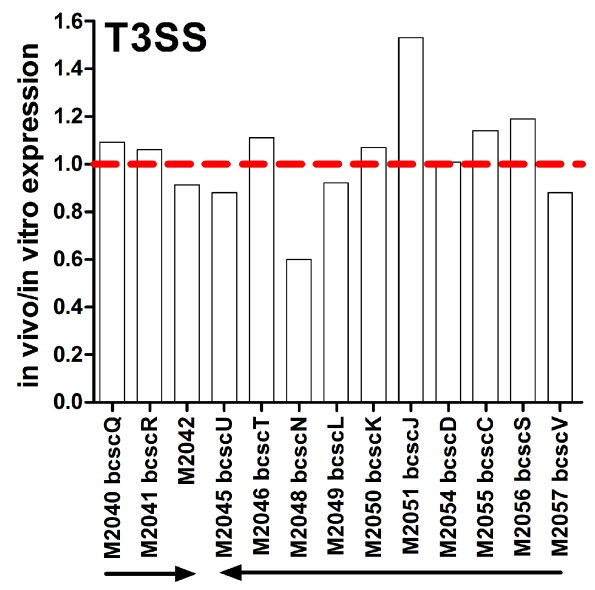

D

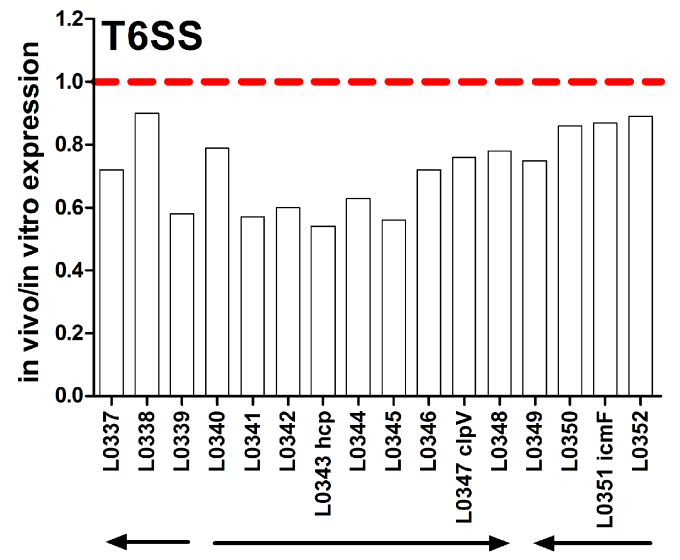

FIGURE 2 | In vivo expression of genes encoding secretion systems. Expression ratio of RNA recovered from rat lungs (in vivo) relative to RNA isolated from in vitro grown cultures as determined by microarray analysis. (A) T2SS, (B) T3SS, (C) T4SS, (D) T6SS. Inset in (C) is chromosome 2-encoded T4SS genes with expanded $y$-axis. The "BCA" designation has been removed from names of genes encoded on chromosomes 1, 2, and 3 for image clarity. Putative operons are indicated by arrows. 
(Engledow et al., 2004). The second T4SS gene cluster exists on a $92.7-\mathrm{kb}$ plasmid that is found in relatively few B. cenocepacia strains including J2315 and K56-2 (Engledow et al., 2004) but not AU1054 or MCO-3 (Winsor et al., 2008). This plasmid-encoded T4SS contributes to the plant tissue watersoaking ( $\mathrm{ptw}$ ) phenotype and disease symptoms in onion tissue (Engledow et al., 2004) and increased survival of $B$. cenocepacia in macrophages and airway epithelial cells (Sajjan et al., 2008). Expression of genes on the

Table 3 | Microarray and qRT-PCR analysis of selected genes showing differential expression from in vivo compared to in vitro grown cultures.

\begin{tabular}{llll}
\hline \multirow{2}{*}{ Gene } & Annotation or predicted function & \multicolumn{2}{c}{ Fold change $^{\mathbf{b}}$} \\
\cline { 3 - 4 } & & microarray & qRT-PCR \\
\hline BCAL0114 & fliC, type Il flagellin protein & -8.29 & -28.00 \\
BCAL0343 & Hcp, hemolysin-coregulated & -1.86 & -7.82 \\
& protein & & \\
BCAL1525 & Flp type pilus subunit & -11.75 & -12.95 \\
BCAM2194 & mmsA, & 2.26 & 1.74 \\
& methylmalonate-semialdehyde & & \\
& dehydrogenase & & \\
BCAM2702 & prpC, 2-methylcitrate synthase & 5.88 & 8.29 \\
pBCA025 & traF, putative conjugative transfer & 7.10 & 344.86 \\
& protein & & \\
pBCA045 & traK, putative exported protein & 12.43 & 33.26 \\
pBCA053 & Putative extracellular & 480.70 & 10.44 \\
& solute-binding protein & & \\
& &
\end{tabular}

${ }^{a}$ Derived from B. cenocepacia J2315 (Holden et al., 2009) at http://www. burkholderia.com Minsor et al., 2008) or http://www.microbesonline.org (Dehal et al., 2009).

${ }^{b}$ Fold change of RNA recovered from rat lungs (in vivo) relative to RNA isolated from in vitro grown cultures as determined by microarray or qRT-PCR analysis. chromosome 2-encoded T4SS were similar in the in vitro and in vivo conditions (Figure 2C). In contrast, several genes that are part of the plasmid-encoded T4SS were markedly induced in vivo at levels ranging from 3- to 46.1-fold (Figure 2C). Higher in vivo expression of pBCA025 encoding the putative conjugative transfer protein TraF and pBCA045 encoding the putative exported protein TraK was confirmed using qRT-PCR (Table 3). These data indicated differential regulation of chromosome 2- and plasmid-encoded T4SS between in vitro and in vivo conditions.

The B. cenocepacia T6SS comprises 16 genes organized in three adjacent operons on chromosome 1 . The T6SS contributes to survival of $B$. cenocepacia in the rat chronic respiratory infection model (Hunt et al., 2004) and influences infection of macrophages (Aubert et al., 2008). Expression of BCAL0339 and BCAL0346 was lower in B. cenocepacia growing in medium supplemented with CF sputum compared to control cultures (Drevinek et al., 2008). In our study, expression of six T6SS genes was lower in vivo compared to in vitro conditions. The BCAL0340-0348 operon exhibited the lowest expression in vivo (0.66) compared to the other two T6SS operons (Figure 2D). The BCAL0340 operon includes genes encoding the ClpV-like chaperone (BCAL0347) and the hemolysin-coregulated protein (Hcp) (BCAL0343; Aubert et al., 2008). The ClpV-like chaperone is required for secretion of Hcp in Pseudomonas aeruginosa (Mougous et al., 2006). The hcp gene showed the lowest in vivo expression (0.54) of any T6SS gene and the low hcp expression in vivo was confirmed using qRT-PCR (Figure 2D; Table 3).

\section{MOTILITY AND FIp TYPE PILUS-ENCODING GENES ARE INDUCED IN VITRO}

Bacterial motility, attachment, and invasion via flagellar- and pilus-encoding genes are known to be important in virulence (Tomich et al., 2002; Urban et al., 2004). Expression of 24 flagellarassociated genes from eight different operons distributed across chromosome 1 was lower in vivo, with the lowest in vivo/in vitro
A

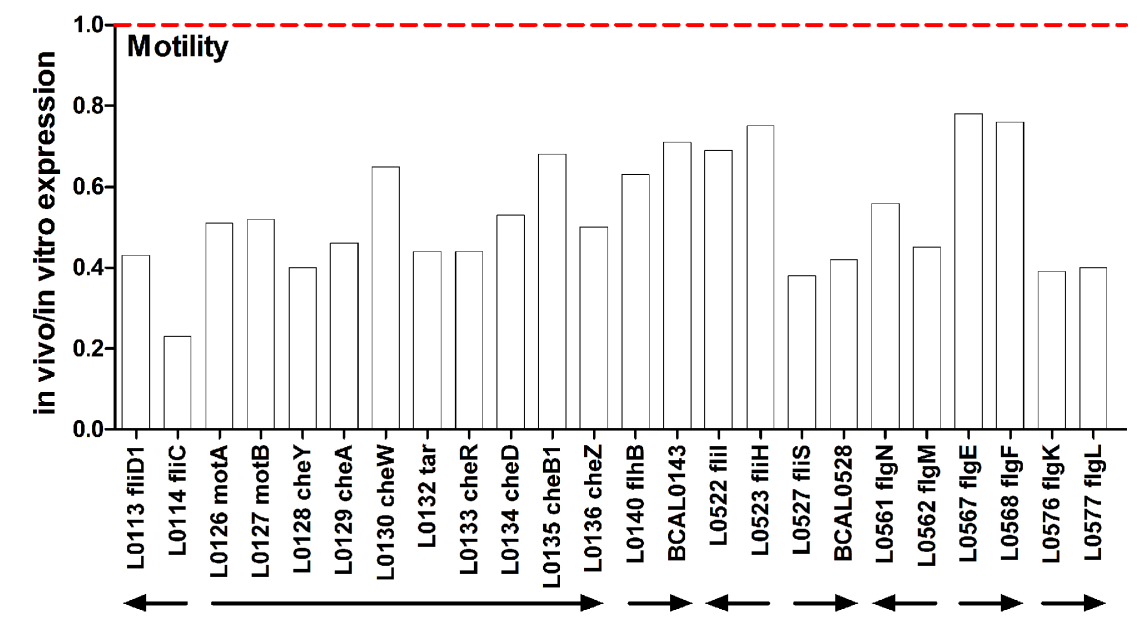

B

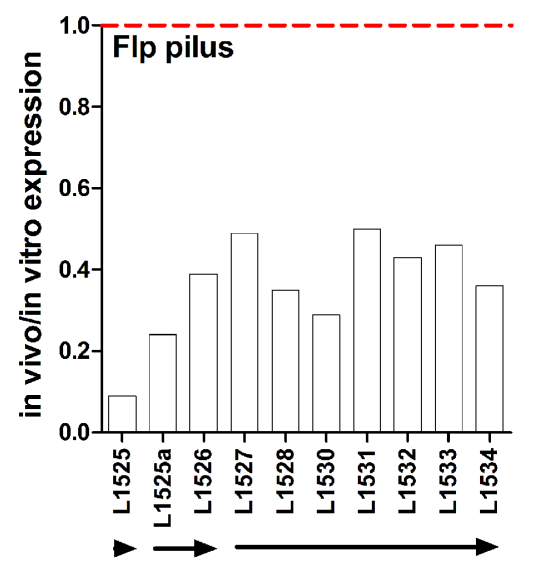

FIGURE 3 | In vivo expression of motility and pilus genes. Expression ratio of RNA recovered from rat lungs (in vivo) relative to RNA isolated from in vitro grown cultures as determined by microarray analysis. (A) Flagellar-associated genes, (B) Flp type pilus genes. The "BCA" designation has been removed from names of genes encoded on chromosomes 1, 2, and 3 for image clarity. Putative operons are indicated by arrows. 
expression ratio (0.23) observed for fliC, encoding type II flagellin (Figure 3A). Lower expresssion of fliC in vivo compared to in vitro conditions was independently confirmed using qRT-PCR (Table 3).

The genomic locus from BCAL1520-1537 encodes components of a subclass of type IVb prepilins, called a Flp type pilus, that is similar to the $f l p-t a d-r c p$ locus that is involved in adherence and biofilm formation in Actinobacillus actinomycetemcomitans (Kachlany et al., 2001; Inoue et al., 2003) and aggregation and biofilm formation in P. aeruginosa (de Bentzmann et al., 2006). Ten genes encoding components of the chromosome 1-encoded Flp type pilus had lower in vivo expression. The lowest expression was observed for BCAL1525 encoding a Flp type pilus subunit and this trend was confirmed using qRT-PCR (Figure 3B; Table 3).

\section{IDENTIFICATION OF GENES POTENTIALLY IMPORTANT IN THE HOST ENVIRONMENT}

Approximately 300 genes were identified with at least a 1.5-fold change increase in expression in vivo compared to in vitro grown cultures (Table A1 in Appendix). Selected genes and their fold change differences are shown in Table 4. Many of these genes have not been previously characterized in B. cenocepacia. The most common putative functions of these in vivo induced genes were related to adaptation to stress or a host environment, metabolism, or nutrient acquisition (Table 4).

\section{NOVEL GENES INDUCED IN VIVO}

A four gene operon (BCAM2703-2700) containing genes involved in the methylcitrate cycle, required for propionyl-CoA metabolism, and fatty-acid utilization, were markedly induced in vivo (Table 4). Induced in vivo expression of BCAM2702 (prpC) encoding 2-methylcitrate synthase was confirmed using qRT-PCR (Table 3). Genes involved in the methylcitrate and glyoxylate cycles are required for virulence in Mycobacterium tuberculosis, which relies more on fatty acids than carbohydrates during infection (Munoz-Elias and McKinney, 2005). Genes involved in the methylcitrate cycle are upregulated in M. tuberculosis isolated from murine macrophages (Schnappinger et al., 2003) and are important for growth in macrophages but not for intracellular survival (Munoz-Elias et al., 2006). It is unknown whether the methylcitrate cycle plays a role in B. cenocepacia intracellular survival in macrophages. An uncharacterized seven gene operon (BCAM2196-BCAM2191) containing genes putatively involved in lipid metabolism was also induced in vivo (Table 4), suggesting that fatty-acid metabolism or utilization may be important in B. cenocepacia lung infections. Using qRT-PCR we confirmed expression of BCAM2194 ( $m m s A$ ) encoding methylmalonatesemialdehyde dehydrogenase was induced in vivo (Table 3). A four gene operon (BCAL1212-1215) induced in vivo encodes genes for a 2-oxo acid dehydrogenase complex (Table 4). The dihydrolipoamide dehydrogenase gene component of a similar complex was shown to be important for persistence and virulence in Streptococcus pneumoniae infection models likely due to having a role in capsule synthesis rather than metabolism of 2-oxo acids (Smith et al., 2002).

BCAM0415 encodes a betaine aldehyde dehydrogenase (BADH; Table 4). In P. aeruginosa, BADH has been shown to
Table 4 | Selected genes induced during chronic lung infection.

\begin{tabular}{|c|c|c|}
\hline Gene & Annotation or predicted function ${ }^{a}$ & Fold change $^{b}$ \\
\hline \multicolumn{3}{|c|}{ OSMOTIC STRESS AND ADAPTATION } \\
\hline BCAL1103 & Putative OsmB-like lipoprotein & 2.1 \\
\hline BCAL2044 & LdcA LD-carboxypeptidase A & 1.5 \\
\hline BCAL2558 & $\begin{array}{l}\text { Pyridine nucleotide-disulfide } \\
\text { oxidoreductase }\end{array}$ & 2.1 \\
\hline BCAL3297 & $\begin{array}{l}\text { DPS-family DNA-binding ferritin like } \\
\text { protein }\end{array}$ & 1.7 \\
\hline BCAL3310 & $\begin{array}{l}\text { Ycel family protein, osmotic, and acid } \\
\text { stress adaptation }\end{array}$ & 1.7 \\
\hline BCAL3311 & $\begin{array}{l}\text { Ycel family protein, osmotic, and acid } \\
\text { stress adaptation }\end{array}$ & 1.6 \\
\hline BCAL3314 & PqiA paraquat inducible protein $\mathrm{A}$ & 2.4 \\
\hline BCAL3362 & Putative oxidoreductase & 1.8 \\
\hline BCAM0027 & $\begin{array}{l}\text { PadR family regulatory protein, phenolic } \\
\text { acid induced stress response }\end{array}$ & 1.5 \\
\hline BCAM0414 & Conserved hypothetical protein & 2.0 \\
\hline BCAM0415 & Putative betaine aldehyde dehydrogenase & 1.5 \\
\hline BCAM2700 & prpF, putative membrane protein & 1.8 \\
\hline BCAM2701 & acnA, aconitate hydratase 1 & 2.7 \\
\hline BCAM2702 & prpC, 2-methylcitrate synthase & 5.9 \\
\hline BCAM2703 & prpB, probable methylisocitrate lyase & 2.8 \\
\hline \multicolumn{3}{|c|}{ METAL ION TRANSPORT OR METABOLISM } \\
\hline BCAL0269 & $\begin{array}{l}\text { Oxidoreductase, molybdopterin-binding } \\
\text { domain }\end{array}$ & 1.6 \\
\hline BCAL0366 & $\begin{array}{l}\text { Nitroreductase family protein, metal ion } \\
\text { oxidation }\end{array}$ & 1.6 \\
\hline BCAL0580 & Putative chromate transport protein & 1.6 \\
\hline BCAL1789 & ExbB, iron-transport protein & 1.7 \\
\hline BCAL2485 & $\begin{array}{l}\text { Putative iron-sulfur cluster-binding } \\
\text { electron }\end{array}$ & 2.1 \\
\hline BCAL2486 & Putative iron-sulfur oxidoreductase & 2.1 \\
\hline BCAM0447 & Putative exported multicopper oxidase & 13.0 \\
\hline BCAM1187 & TonB-dependent siderophore receptor & 1.7 \\
\hline BCAM1527 & Putative cation efflux protein & 1.8 \\
\hline BCAM2007 & TonB-dependent siderophore receptor & 1.6 \\
\hline BCAS0028 & $\begin{array}{l}\text { Succinylglutamate } \\
\text { desuccinylase/aspartoacylase }\end{array}$ & 2.8 \\
\hline BCAS0449 & $\begin{array}{l}\text { Nickle ion binding-protein-dependent } \\
\text { transport }\end{array}$ & 1.6 \\
\hline \multicolumn{3}{|c|}{ CARBOHYDRATE TRANSPORT AND METABOLISM } \\
\hline BCAL0804 & $\mathrm{N}$-acetylglucosamine transferase & 1.5 \\
\hline BCAL1657 & Putative ribose transport system & 1.8 \\
\hline BCAL1658 & $\begin{array}{l}\text { Putative ribose } A B C \text { transporter } \\
\text { ATP-binding }\end{array}$ & 1.5 \\
\hline BCAL1754 & $\begin{array}{l}\text { Major facilitator superfamily protein, } \\
\text { carbohydrate transport }\end{array}$ & 3.5 \\
\hline BCAL2040 & $\begin{array}{l}\text { Polysaccharide deacetylase, carbohydrate } \\
\text { transport }\end{array}$ & 1.5 \\
\hline BCAL3038 & $\begin{array}{l}\text { ABC transporter ATP-binding component, } \\
\text { carbohydrate } A B C \text { transporter }\end{array}$ & 1.6 \\
\hline BCAL3039 & $\mathrm{ABC}$ transporter, membrane permease & 1.5 \\
\hline BCAL3040 & $\mathrm{ABC}$ transporter, membrane permease & 1.7 \\
\hline
\end{tabular}

(Continued) 
Table 4 | Continued

\begin{tabular}{|c|c|c|}
\hline Gene & Annotation or predicted function ${ }^{a}$ & Fold change $^{b}$ \\
\hline BCAL3041 & MalE, maltose-binding protein & 2.1 \\
\hline BCAL3364 & Putative gluconokinase & 1.7 \\
\hline BCAM0094 & Xylulose kinase & 1.7 \\
\hline BCAM1330 & Cellulose polysaccharide export protein & 1.7 \\
\hline BCAM1333 & $\begin{array}{l}\text { Cellulose exopolysaccharide } \\
\text { acyltransferase }\end{array}$ & 1.6 \\
\hline BCAM1390 & Putative aldolase & 3.0 \\
\hline BCAM2260 & Major facilitator superfamily protein & 1.6 \\
\hline BCAS0230 & $\begin{array}{l}\text { Putative sugar ABC transporter } \\
\text { ATP-binding }\end{array}$ & 1.6 \\
\hline \multicolumn{3}{|c|}{ AMINO ACID TRANSPORT AND METABOLISM } \\
\hline BCAL0446 & Putative aminotransferase & 2.9 \\
\hline BCAL1212 & $\begin{array}{l}\text { bkdA1, 2-oxoisovalerate dehydrogenase } \\
\text { alpha subunit }\end{array}$ & 3.0 \\
\hline BCAL1213 & $\begin{array}{l}\text { bkdA2, 2-oxoisovalerate dehydrogenase } \\
\text { beta subunit }\end{array}$ & 2.9 \\
\hline BCAL1214 & bhdB, lipoamide acyltransferase & 3.7 \\
\hline BCAL1215 & IpdV, dihydrolipoamide dehydrogenase & 2.2 \\
\hline BCAL1749 & Putative CoA-transferase & 2.4 \\
\hline BCAL1750 & $\begin{array}{l}\text { Conserved hypothetical protein, pyruvate } \\
\text { decarboxylase }\end{array}$ & 2.4 \\
\hline BCAL1751 & $\begin{array}{l}\text { Glyoxalase/bleomycin resistance, amino } \\
\text { acid transport }\end{array}$ & 1.7 \\
\hline BCAM0047 & Lysine exporter - LysE/YggA & 2.6 \\
\hline BCAM0178 & $\begin{array}{l}\text { ABC transporter periplasmic } \\
\text { solute-binding protein }\end{array}$ & 2.7 \\
\hline BCAM0368 & $\begin{array}{l}\text { Putative branched-chain amino acid } \\
\text { transport }\end{array}$ & 1.5 \\
\hline BCAM0459 & Cysteine desulfurase & 3.6 \\
\hline BCAM0983 & $\begin{array}{l}\text { leuC1, 3-isopropylmalate dehydratase } \\
\text { large subunit }\end{array}$ & 2.9 \\
\hline BCAM0983A & $\begin{array}{l}\text { Putative entericidin B-like bacteriolytic } \\
\text { toxin }\end{array}$ & 2.0 \\
\hline BCAM0984 & $\begin{array}{l}\text { leuD1, 3-isopropylmalate dehydratase } \\
\text { small subunit }\end{array}$ & 2.1 \\
\hline BCAM1150 & 3-Hydroxyisobutyrate dehydrogenase & 1.6 \\
\hline BCAM1151 & $\begin{array}{l}\text { Methylmalonate-semialdehyde } \\
\text { dehydrogenase }\end{array}$ & 2.4 \\
\hline BCAM1427 & LysE family transporter & 3.7 \\
\hline BCAM1487 & $\begin{array}{l}\text { Putative ABC transporter, } \\
\text { substrate-binding }\end{array}$ & 3.1 \\
\hline BCAM1488 & Putative proline racemase & 1.9 \\
\hline BCAM2095 & Putative HTH transcriptional regulator & 1.6 \\
\hline BCAM2096 & $\begin{array}{l}\text { puuB gamma-glutamylputrescine } \\
\text { oxidoreductase }\end{array}$ & 1.9 \\
\hline BCAM2191 & Enoyl-CoA hydratase/isomerase family & 1.9 \\
\hline BCAM2192 & $\begin{array}{l}\text { Enoyl-CoA hydratase/isomerase family } \\
\text { protein }\end{array}$ & 2.4 \\
\hline BCAM2193 & $\begin{array}{l}\text { mmsB, 3-hydroxyisobutyrate } \\
\text { dehydrogenase }\end{array}$ & 2.4 \\
\hline BCAM2194 & $\begin{array}{l}\text { mmsA, methylmalonate-semialdehyde } \\
\text { dehydrogenase }\end{array}$ & 2.3 \\
\hline
\end{tabular}

\begin{tabular}{|c|c|c|}
\hline Gene & Annotation or predicted function ${ }^{a}$ & Fold change $^{b}$ \\
\hline BCAM2195 & Putative AMP-binding enzyme & 2.5 \\
\hline BCAM2196 & Putative acyl-CoA dehydrogenase & 2.1 \\
\hline BCAM2237 & Putative 2,2-dialkylglycine decarboxylase & 2.4 \\
\hline BCAS0397 & Metallo peptidase, subfamily M20D & 2.0 \\
\hline BCAS0443 & $\begin{array}{l}\text { Putative binding-protein-dependent } \\
\text { transport }\end{array}$ & 5.3 \\
\hline BCAS0574 & $\begin{array}{l}\text { Amino acid } A B C \text { transporter ATP-binding } \\
\text { protein }\end{array}$ & 3.7 \\
\hline BCAS0575 & $\begin{array}{l}\text { Putative binding-protein-dependent } \\
\text { transport }\end{array}$ & 2.0 \\
\hline BCAS0577 & Periplasmic solute-binding protein & 1.5 \\
\hline \multicolumn{3}{|c|}{ MEMBRANE PROTEINS } \\
\hline BCAL0403 & $\begin{array}{l}\text { Putative outer membrane-bound lytic } \\
\text { murein }\end{array}$ & 1.5 \\
\hline BCAL0624 & $\begin{array}{l}\text { Putative OmpC, outer membrane porin } \\
\text { protein precursor }\end{array}$ & 1.6 \\
\hline BCAL1678 & $\begin{array}{l}\text { Putative outer membrane usher protein } \\
\text { precursor, fimD pilin biogenesis }\end{array}$ & 2.4 \\
\hline BCAL2083 & $\begin{array}{l}\text { YaeT, Outer membrane protein assembly } \\
\text { factor }\end{array}$ & 1.5 \\
\hline BCAL2191 & $\begin{array}{l}\text { Putative } 17 \mathrm{kDa} \text { membrane protein } \\
\text { surface antigen }\end{array}$ & 3.1 \\
\hline BCAL2468 & Putative membrane protein & 1.9 \\
\hline BCAL2482 & Putative OmpC outer membrane protein & 3.1 \\
\hline BCAL2505 & Putative membrane protein & 1.5 \\
\hline BCAL2552 & Putative membrane protein & 1.5 \\
\hline BCAL2553 & Putative membrane protein & 1.8 \\
\hline BCAL3033 & $\begin{array}{l}\text { Probable outer membrane lipoprotein } \\
\text { carrier }\end{array}$ & 1.5 \\
\hline BCAL3203 & Putative periplasmic TolB protein & 1.6 \\
\hline BCAL3204 & Putative OmpA family lipoprotein/PAL & 1.7 \\
\hline BCAL3205 & YbgF,Tol-PAL system protein & 1.6 \\
\hline BCAL3473 & $\begin{array}{l}\text { Putative OmpC-like outer membrane } \\
\text { porin }\end{array}$ & 1.9 \\
\hline BCAM0926 & $\begin{array}{l}\text { Multidrug efflux system transporter } \\
\text { protein }\end{array}$ & 5.9 \\
\hline BCAM1207 & $\begin{array}{l}\text { ABC transporter ATP-binding membrane } \\
\text { protein }\end{array}$ & 1.5 \\
\hline BCAM1341 & Acyltransferase like protein & 3.2 \\
\hline BCAM1425 & Putative membrane protein & 2.9 \\
\hline BCAM1563 & $\begin{array}{l}\text { ABC transporter ATP-binding membrane } \\
\text { protein }\end{array}$ & 1.7 \\
\hline BCAM1946 & $\begin{array}{l}\text { Putative quinoxaline efflux system } \\
\text { transporter }\end{array}$ & 1.6 \\
\hline BCAM1957 & ABC transporter ATP-binding protein & 1.6 \\
\hline BCAM2647 & Putative membrane protein & 1.7 \\
\hline BCAM2648 & $\begin{array}{l}\text { NAD dependent epimerase/dehydratase } \\
\text { family, outer membrane biogenesis }\end{array}$ & 1.6 \\
\hline BCAS0308 & $\begin{array}{l}\text { Putative flp type pilus assembly protein, } \\
\text { TadG-like pilus }\end{array}$ & 2.4 \\
\hline BCAS0463 & Putative membrane protein & 1.6 \\
\hline pBCA010 & Putative membrane protein & 3.2 \\
\hline
\end{tabular}

(Continued) 
Table 4 | Continued

\begin{tabular}{|c|c|c|}
\hline Gene & Annotation or predicted function ${ }^{a}$ & Fold change $^{b}$ \\
\hline pBCA014 & Putative membrane protein & 3.3 \\
\hline pBCA019 & Putative membrane protein & 2.4 \\
\hline pBCA026 & Putative membrane protein & 10.6 \\
\hline pBCA029 & Putative membrane protein & 8.6 \\
\hline pBCA034 & Putative membrane protein & 6.0 \\
\hline pBCA036 & Putative membrane protein & 13.8 \\
\hline pBCA037 & Putative membrane protein & 7.3 \\
\hline pBCA048 & Putative membrane protein & 55.6 \\
\hline \multicolumn{3}{|c|}{ EXPORTED PROTEINS } \\
\hline BCAL0305 & Putative exported protein & 2.2 \\
\hline BCAL0623 & Putative exported protein & 1.7 \\
\hline BCAL1279 & Putative exported protein & 1.6 \\
\hline BCAL1499 & Putative exported protein & 1.8 \\
\hline BCAL1539 & Putative exported protein & 2.3 \\
\hline BCAL1798 & Putative exported protein & 1.9 \\
\hline BCAL1961 & Putative exported protein & 1.9 \\
\hline BCAL2187 & Putative exported protein & 1.6 \\
\hline BCAL2607 & Putative exported protein & 2.7 \\
\hline BCAL2615 & $\begin{array}{l}\text { Putative exported outer membrane porin } \\
\text { protein }\end{array}$ & 2.2 \\
\hline BCAL2911 & Proline-rich exported protein & 1.6 \\
\hline BCAL2956 & Putative exported protein & 1.5 \\
\hline BCAL3024 & Putative exported protein & 1.6 \\
\hline BCAL3490 & Putative exported protein & 2.0 \\
\hline BCAL3492 & Putative exported protein & 1.6 \\
\hline BCAM0676 & Putative exported protein & 1.8 \\
\hline BCAM1726 & Putative exported protein & 2.0 \\
\hline BCAM1742 & Putative exported protein & 1.9 \\
\hline BCAM1964 & Putative exported protein & 1.6 \\
\hline BCAM2073 & Putative exported protein & 3.0 \\
\hline pBCA013 & Putative exported protein & 6.3 \\
\hline \multicolumn{3}{|c|}{ REGULATORY PROTEINS } \\
\hline BCAL2488 & LysR family regulatory protein & 2.0 \\
\hline BCAL2529 & LysR family regulatory protein & 1.5 \\
\hline BCAL3486 & $\begin{array}{l}\text { ecfM, RNA polymerase sigma factor, } \\
\text { sigma-70 }\end{array}$ & 1.8 \\
\hline BCAM0422 & LuxR superfamily regulatory protein & 1.9 \\
\hline BCAM0595 & LysR family regulatory protein & 2.6 \\
\hline BCAM2025 & Sigma-54 interacting regulatory protein & 1.9 \\
\hline BCAM2162 & MarR family regulatory protein & 2.0 \\
\hline BCAS0436 & AraC family regulatory protein & 1.7 \\
\hline pBCA035 & GntR family regulatory protein & 18.9 \\
\hline
\end{tabular}

${ }^{a}$ Derived from B. cenocepacia J2315 (Holden et al., 2009) at http://wWw. burkholderia.com Minsor et al., 2008) or http://www.microbesonline.org (Dehal et al., 2009).

${ }^{b}$ Fold change of RNA recovered from rat lungs (in vivo) relative to RNA isolated from in vitro grown cultures as determined by microarray analysis.

be induced by choline and choline precursors (Velasco-Garcia et al., 2006a) which are abundant in infected lung tissues (Wright and Clements, 1987). In addition to playing a role in assimilating carbon and nitrogen from choline, BADH produces glycine betaine which can protect bacteria from high osmolarity stress and oxidative stress in infected tissues. BADH has been proposed as a therapeutic target for $P$. aeruginosa since inactivation of this enzyme leads to intracellular accumulation of betaine aldehyde, which is toxic, and the inability to grow in medium with choline (Velasco-Garcia et al., 2006b; Zaldivar-Machorro et al., 2011). Homologs of other genes induced by osmotic stress in bacteria were also identified as being induced in vivo (Table 4). BCAL1103, encodes an OsmB-like protein. OsmB is induced by osmotic stress and stationary phase growth conditions in E. coli (Jung et al., 1990; Boulanger et al., 2005). BCAL3310 and BCAL3311 are predicted to be co-transcribed YceI family proteins, homologs of which have been shown to be induced in response to osmotic stress in E. coli (Weber et al., 2006) and acid stress in Helicobacter pylori (Sisinni et al., 2010). BCAL2558, a putative pyridine nucleotide-disulfide oxidoreductase with some similarity to $\operatorname{TrxB}$ (thioredoxin reductase) homologs, was induced twofold in vivo. $\operatorname{TrxB}$ genes are involved in cellular redox processes and defense against oxidative stress and are important in intracellular survival in some pathogens (Bjur et al., 2006; Potter et al., 2009). BCAL3314 encodes a homolog of PqiA-like proteins, which are induced by paraquat and other superoxide generators in E. coli (Koh and Roe, 1995). BCAL3297 encodes a DPS-family DNA-binding ferritin. Homologs of these proteins are involved in resistance as well as iron sequestration (Calhoun and Kwon, 2011).

Although many of the in vivo induced outer membrane protein encoding genes are uncharacterized, a few have homology to proteins with predicted functions. BCAL3203, L3204, and L3205 form part of the Tol-PAL system membrane complex that is required for membrane integrity and has been implicated in the pathogenesis of several Gram-negative bacteria (Bowe et al., 1998; Godlewska et al., 2009; Paterson et al., 2009). TolB (BCAL3203) is a periplasmic protein involved in biopolymer transport. BCAL3205 is a YbgF homolog which is the last gene of the Tol-PAL complex and interacts with TolA (Krachler et al., 2010). BCAL3204 has been annotated as OmpA/PAL. PAL has been shown to contribute to virulence in several Gram-negative bacteria and in E. coli has been shown to be released into the bloodstream contributing to septic shock (Hellman et al., 2002; Liang et al., 2005). A $17 \mathrm{kDa}$ OmpA-like protein has recently been shown to be an immunodominant antigen following intranasal immunization with a $B$. cenocepacia outer membrane protein preparation in mice (Makidon et al., 2010). Although the immunoreactive protein reported to be an OmpA-like protein was not conclusively identified, the partial amino acid sequence determined from a peptide of this molecular mass isolated from SDS-polyacrylamide gels, has $95.8 \%$ identity to BCAL3204. There are at least six other OmpA-like proteins in B. cenocepacia with varying degrees of sequence identify; however, PAL has been shown to highly immunogenic in other bacteria (Godlewska et al., 2009). Therefore it is possible that the immunodominant antigen identified by Makidon et al. (2010) is PAL. BCAL2191, which was increased threefold in vivo (Table 4) is predicted to be an outer membrane lipoprotein with similarity to $17 \mathrm{kDa}$ surface antigens in other species and therefore it is also possible that this protein contributed to the observed reaction with antiserum on Western blots in the study by Makidon et al. (2010). Several other proteins involved in biogenesis of membrane and other cell surface components were also identified (Table 4) including BCAL2083, a YaeT homolog, which in E. coli is an essential gene required for outer membrane assembly 
(Werner and Misra, 2005). BCAL2482 is a putative outer membrane porin $(\mathrm{OmpC})$ and is in the same predicted operon as BCAL2486 and BCAL2485, which are iron-sulfur oxidoreductase and iron-sulfur electron transport proteins, respectively. All three genes are induced at least twofold in vivo (Table 4).

Although ornibactin biosynthesis and uptake genes were expressed at similar levels in the in vitro and in vivo conditions used in this study, a number of other genes potentially involved in metal ion transport and metabolism were identified as being induced in vivo (Table 4). These included exbB, genes coding for iron-sulfur proteins and receptors for unknown siderophores. One of the most highly induced genes in vivo was BCAM0447 which encodes a putative multicopper oxidase (MCO). MCO genes are found in a number of genomes but have only recently been characterized. The MCO protein of P. aeruginosa has been shown to be involved in the oxidation of ferrous to ferric iron and may be important in iron acquisition (Huston et al., 2002). MCO homologs are also involved in copper resistance and dissemination in mice in S. typhimurium (Achard et al., 2010) and copper tolerance in Campylobacter jejuni (Hall et al., 2008).

Genes encoding proteins of unknown function induced in vivo are shown in Table $\mathbf{4}$ and Table A1 in Appendix. Many of the expressed genes encode outer membrane proteins (11) and exported proteins (24) that could contribute to cell surface alterations or virulence. Genes encoding six hypothetical proteins were unique to B. cenocepacia (Table A1 in Appendix), whereas, 23 genes encoding hypothetical proteins were conserved in one or more members of the Bcc, of which 11 were also conserved in Burkholderia pseudomallei (Table A1 in Appendix). It is possible that these proteins are involved in adaptation, survival, or virulence in lung infections although further studies are required to determine their potential importance.

\section{PLASMID-ASSOCIATED GENES}

Interestingly, the most highly induced genes in vivo were located on the plasmid where the vast majority of the genes were expressed at much higher levels in vivo than in vitro (Figure 4). Of the plasmid genes annotated in the J2315 sequence (Winsor et al., 2008), 62 genes had higher expression in the lung infection model. Only one gene, pBCA055, had higher expression levels in vitro, and the following genes had similar expression: pBCA003-007, 061, 063, 064, 066-075, 078-081, 083-086, 091-094.

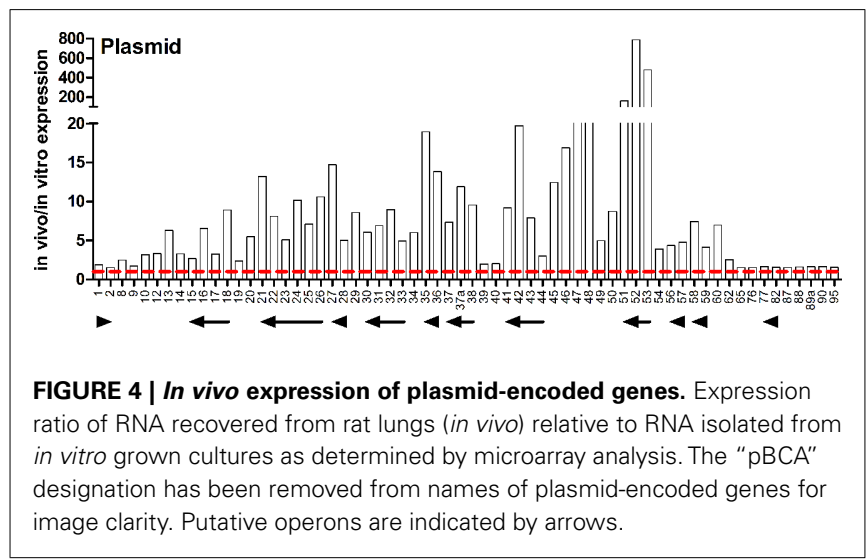

Many of the highly induced genes are part of the plasmidencoded T4SS, which has been shown to play a role in both plant pathogenesis and survival in eukaryotic cells (Engledow et al., 2004; Sajjan et al., 2008). Expression ratios of genes known or predicted to be a part of the T4SS are shown in Figure $2 \mathrm{C}$ and described above. The presence of the plasmid-encoded T4SS in the B. cenocepacia ET12 lineage strains J2315 and K56-2 but not AU1054 or MCO-3 that entirely lack a plasmid is an interesting characteristic. Gene expression of pBCA054 encoding a LuxR family regulatory protein was higher in vivo. Interestingly, the most closely related pBCA054 orthologs are found in B. pseudomallei and Burkholderia mallei, rather than in other members of the Bcc. pBCA001-002 are parAB-like homologs that are putatively involved in chromosome partitioning. pBCA017 is similar to the zeta toxin family of toxin-antitoxin complexes which are involved in programmed cell death to prevent proliferation of plasmid free cells (Gerdes et al., 2005). In addition to plasmid maintenance, toxin-antitoxin pairs can also be involved in responding to nutrient stress. Zeta toxins have recently been shown to target peptidoglycan synthesis triggering autolysis (Mutschler et al., 2011). Zeta toxins are typically paired with epsilon antitoxins; however, there does not appear to be an epsilon homolog adjacent to pBCA017. In some cases, a chromosomal antitoxin can neutralize the plasmid toxin, but in this case toxin expression would not favor plasmid maintenance (Van Melderen and Saavedra De Bast, 2009). Alternatively the toxin can be integrated into other regulatory networks or serve to reduce the overall population to increase nutrient availability for the survivors. Three genes forming an operon (pBCA053-051) exhibited the highest induction of any group of genes in vivo (Figure 4). pBCA053 encodes a extracellular solute-binding protein involved in dicarboxylate transporter carbohydrate metabolism and we confirmed higher in vivo expression of this gene using qRT-PCR (Table 3 ). The second and third genes in the operon encode an exported protein and a protein with homology to LamB/YcsF family proteins, respectively. In addition to the hypothetical proteins noted above, four putative exported proteins, nine putative membrane proteins, 12 conserved hypothetical proteins and 10 hypothetical proteins encoded on the plasmid were induced in vivo (Table A1 in Appendix). Few genes on this plasmid have been studied in detail opening the possibility for identifying proteins with potentially novel functions.

\section{DISCUSSION}

In this study, we have identified the gene expression signature of $B$. cenocepacia during lung infections. To the best of our knowledge, this is the first study to apply transcriptomics for any member of the Bcc to study gene expression during infection of a susceptible host. Differential gene expression was observed for characterized virulence genes as well as potential novel virulence genes between in vitro and in vivo environments.

Altered in vivo gene expression was observed for genes encoding enzymes, regulators, structural appendages as well as those contributing to ornibactin biosynthesis, and quorum sensing systems. Lower in vivo expression was observed for AHL-dependent QS controlled genes that are directly (e.g., aidA) and indirectly (e.g., $s h v R$ ) regulated at the transcriptional level by CepR (Weingart et al., 2005; O'Grady et al., 2011). These observations suggest that 
more favorable conditions exist for CepIR-dependent regulation of selected genes in high cell-density $\left(\sim 10^{9}\right)$ laboratory-grown cultures compared to the lower cell-density $\left(\sim 10^{5}\right)$ in the lung infections, although it is possible that higher expression of QS regulated genes occurs in selected locations in the lungs where bacteria are present in high cell-density biofilms. Since cepI and CepRregulated genes including $z m p A, z m p B$, and $s h v R$ have been shown to be important for virulence in the rat chronic respiratory infection model (Corbett et al., 2003; Sokol et al., 2003; Kooi et al., 2006; Bernier et al., 2008), it is clear that these genes are expressed at sufficient levels to play a role in infection. The majority of characterized virulence genes were similarly expressed in the in vivo and in vivo conditions. This suggests that expression of these genes is just as important in high cell-density cultures and during lung infections. The contribution of these individual genes has been characterized in one or more infection models highlighting their importance in B. cenocepacia pathogenesis. Similar expression of characterized virulence genes during growth in vivo in hamsters and in vitro has previously been observed for B. pseudomallei (Tuanyok et al., 2006).

Increased expression of some genes belonging to the T3SS was observed in the closely related pathogens B. mallei and B. pseudomallei during infection of mice and hamsters, respectively (Kim et al., 2005; Tuanyok et al., 2006). In the present study, expression of T2SS and T3SS genes was similar between in vitro and in vivo environments. Genes in these secretion systems appear to be expressed at moderate levels in both in vitro and in vivo environments. We previously showed expression of the T2SS genes $g s p C$ and $g s p G$ was influenced by growth medium composition (O'Grady et al., 2011). A previous study was not able to identify growth conditions that altered expression of T3SS genes suggesting these genes are constitutively expressed (Engledow et al., 2004). The in vivo growth conditions provided a stimulus for expression of genes in the plasmid-encoded T4SS but did not affect expression of the T4SS genes on chromosome 2. A mutation in the chromosome 2-encoded T4SS was shown not to contribute to bacterial persistence or histopathology in the rat chronic respiratory infection model (Bernier and Sokol, 2005). To date, no studies have observed such a dramatic increase in expression of plasmid-encoded T4SS genes suggesting that specific environmental signal(s) in the lung environment enabled increased expression of these genes to be detected. It was shown that the plasmid-encoded T4SS contributed to onion tissue maceration through secretion of one or more effectors (Engledow et al., 2004). Whether this plasmid-encoded T4SS or its effectors have a role in mammalian cell/tissue damage has yet to be determined. We observed some T6SS genes had lower in vivo expression, in particular those genes on the BCAL0340 operon that includes a gene encoding the secreted effector Hcp. Previous work identified a transposon insertion in each of the three operons of the T6SS locus affected survival of B. cenocepacia in the rat chronic respiratory infection model (Hunt et al., 2004).

Using a mouse agar bead infection model, a flagellin mutant failed to cause mortality compared to wild type (Urban et al., 2004). It was also shown that motility mutants were less able to invade epithelial cells (Tomich et al., 2002). Recent work showed expression of flagellar- and chemotaxis-associated genes and motility was reduced in B. cenocepacia strains of the ET12 lineage that were isolated from CF patients (Sass et al., 2011). However, a previous study showed transcription of flagellar-associated genes was increased in B. cenocepacia J2315 cultured in medium supplemented with CF sputum (Drevinek et al., 2008). Conflicting data regarding expression of flagellar-associated genes in these two studies likely reflect the experimental conditions employed where increased expression of flagellar-associated genes was detected in rapidly growing cultures (Drevinek et al., 2008). The phenotypic characteristics of the B. cenocepacia non-motile $\mathrm{CF}$ isolates are similar to $P$. aeruginosa clinical isolates which often acquire loss-of-function mutations associated with motility during chronic lung infection (Mahenthiralingam et al., 1994). It has also been shown that $P$. aeruginosa exhibited decreased transcription of flagellar-associated genes when cultured in CF sputum (Wolfgang et al., 2004). In our study, we detected lower in vivo expression of genes involved in motility and Flp type pilus formation. This result was likely due to differences in culture conditions between in vitro and in vivo environments. The agar bead infection model bypasses the colonization step during infection (Cash et al., 1979). Our data suggest expression of these genes is not required in an established infection taking place in the lower respiratory tract. Therefore, decreased expression of these genes was expected since expression of these genes is an energy-expensive process and is more likely associated with rapidly growing cultures than cultures recovered from chronic lung infection.

We identified numerous genes that were induced during lung infections. Many of these genes encode proteins with functions related to metabolism, physiology, or adaptation to a stressful environment. While homologs of some of these proteins have been studied in other pathogens, these proteins have not been specifically studied in B. cenocepacia. Several B. cenocepacia ET12 lineage strains contain at least a $45-\mathrm{kb}$ fragment of the plasmid found in K56-2 and J2315 (Engledow et al., 2004) while strains AU1054 and MCO-3 lack a plasmid (Winsor et al., 2008). While plasmid-minus derivatives of B. cenocepacia J2315 or K56-2 have not been reported, it would be interesting to determine what influence absence of the plasmid may have on infection considering the vast majority of plasmid-encoded genes were induced in vivo. Further confirmatory experiments are required to substantiate trends for additional genes that exhibited altered expression in the in vivo environmental conditions. Revealing the changes in gene expression that occur in bacterial cells during infection is a first step in understanding the response of bacterial cells to the host environment. Increased expression of genes during infection suggests these genes promote bacterial survival and adaptation in the lungs and potentially influence virulence. The identification of potential novel virulence genes among these in vivo induced genes provides an opportunity to characterize these genes in more detail in future studies. Determining what growth conditions alter the expression of these genes and how they are regulated in $B$. cenocepacia will shed light on their expression pattern. Increased expression of genes during lung infection could be due to a change in environmental cues that enable transcriptional activation by a positive regulator(s) or derepression by a negative regulator(s). For potentially novel virulence genes, it will be important to construct mutations and examine their influence on virulence-related 
phenotypes and pathogenesis in one or more infection models. This study provides an insight into B. cenocepacia gene expression in vivo and may provide opportunities to devise strategies to reduce or control B. cenocepacia lung infections.

\section{ACKNOWLEDGMENTS}

These studies were supported by research grants from Cystic Fibrosis Canada, Cystic Fibrosis Foundation Therapeutics (CFFT)

\section{REFERENCES}

Achard, M. E., Tree, J. J., Holden, J. A., Simpfendorfer, K. R., Wijburg, O. L., Strugnell, R. A., Schembri, M. A., Sweet, M. J., Jennings, M. P., and McEwan, A. G. (2010). The multicopper-ion oxidase CueO of Salmonella enterica serovar Typhimurium is required for systemic virulence. Infect. Immun. 78, 2312-2319.

Aubert, D. F., Flannagan, R. S., and Valvano, M. A. (2008). A novel sensor kinase-response regulator hybrid controls biofilm formation and type VI secretion system activity in Burkholderia cenocepacia. Infect. Immun. 76, 1979-1991.

Baldwin, A., Mahenthiralingam, E., Thickett, K. M., Honeybourne, D., Maiden, M. C., Govan, J. R., Speert, D. P., LiPuma, J. J., Vandamme, P., and Dowson, C. G. (2005). Multilocus sequence typing scheme that provides both species and strain differentiation for the Burkholderia cepacia complex. J. Clin. Microbiol. 43, 4665-4673.

Baldwin, A., Sokol, P. A., Parkhill, J., and Mahenthiralingam, E. (2004). The Burkholderia cepacia epidemic strain marker is part of a novel genomic island encoding both virulence and metabolism-associated genes in Burkholderia cenocepacia. Infect. Immun. 72, 1537-1547.

Bazzini, S., Udine, C., Sass, A., Pasca, M. R., Longo, F., Emiliani, G., Fondi, M., Perrin, E., Decorosi, F., Viti, C., Giovannetti, L., Leoni, L., Fani, R., Riccardi, G., Mahenthiralingam, E., and Buroni, S. (2011). Deciphering the role of RND efflux transporters in Burkholderia cenocepacia. PLoS ONE 6, e18902. doi:10.1371/journal.pone.0018902

Bernier, S. P., Nguyen, D. T., and Sokol, P. A. (2008). A LysR-type transcriptional regulator in Burkholderia cenocepacia influences colony morphology and virulence. Infect. Immun. 76, 38-47.

Bernier, S. P., Silo-Suh, L., Woods, D. E., Ohman, D. E., and Sokol, P. A. (2003). Comparative analysis of plant and animal models for characterization of Burkholderia cepacia virulence. Infect. Immun. 71,
5306-5313.

Bernier, S. P., and Sokol, P. A. (2005). Use of suppression-subtractive hybridization to identify genes in the Burkholderia cepacia complex that are unique to Burkholderia cenocepacia. J. Bacteriol. 187, 5278-5291.

Bjur, E., Eriksson-Ygberg, S., Aslund, F., and Rhen, M. (2006). Thioredoxin 1 promotes intracellular replication and virulence of Salmonella enterica serovar Typhimurium. Infect. Immun. 74, 5140-5151.

Boulanger, A., Francez-Charlot, A., Conter, A., Castanie-Cornet, M. P., Cam, K., and Gutierrez, C. (2005). Multistress regulation in Escherichia coli: expression of osmB involves two independent promoters responding either to sigmas or to the RcsCDB His-Asp phosphorelay. J. Bacteriol. 187, 3282-3286.

Bowe, F., Lipps, C. J., Tsolis, R. M., Groisman, E., Heffron, F., and Kusters, J. G. (1998). At least four percent of the Salmonella typhimurium genome is required for fatal infection of mice. Infect. Immun. 66, 3372-3377.

Calhoun, L. N., and Kwon, Y. M. (2011). Structure, function and regulation of the DNA-binding protein Dps and its role in acid and oxidative stress resistance in Escherichia coli: a review. J. Appl. Microbiol. 110, 375-386.

Cash, H. A., Woods, D. E., McCullough, B., Johanson, W. G. Jr., and Bass, J. A. (1979). A rat model of chronic respiratory infection with Pseudomonas aeruginosa. Am. Rev. Respir. Dis. 119, 453-459.

Castonguay-Vanier, J., Vial, L., Tremblay, J., and Deziel, E. (2010). Drosophila melanogaster as a model host for the Burkholderia cepacia complex. PLoS ONE 5, el1467. doi:10.1371/journal.pone. 0011467

Coenye, T., Van Acker, H., Peeters, E., Sass, A., Buroni, S., Riccardi, G., and Mahenthiralingam, E. (2011). Molecular mechanisms of chlorhexidine tolerance in Burkholderia cenocepacia biofilms. Antimicrob. Agents Chemother. 55, 1912-1919.

Corbett, C. R., Burtnick, M. N., Kooi, C., Woods, D. E., and Sokol, P. A. (2003).

(grant SOKOL06V0), and Canadian Institutes of Health Research (grant MOP-42510) to PAS. EPO was the recipient of a Cystic Fibrosis Canada fellowship. We thank S. A. McKeon and D. F. Viteri for performing the animal experiments and D. T. Nguyen for excellent technical assistance. Microarray processing and initial data assessment was provided by the Mahenthiralingam Laboratory, Cardiff University, with support from CFFT.

An extracellular zinc metalloprotease gene of Burkholderia cepacia. Microbiology 149, 2263-2271.

de Bentzmann, S., Aurouze, M., Ball, G., and Filloux, A. (2006). FppA, a novel Pseudomonas aeruginosa prepilin peptidase involved in assembly of type IVb pili. J. Bacteriol. 188 4851-4860.

Dehal, P. S., Joachimiak, M. P., Price, M. N., Bates, J. T., Baumohl, J. K., Chivian, D., Friedland, G. D., Huang, K. H., Keller, K., Novichkov, P. S., Dubchak, I. L., Alm, E. J., and Arkin, A. P. (2009). MicrobesOnline: an integrated portal for comparative and functional genomics. Nucleic Acids Res. 38, D396-D400.

Drevinek, P., Holden, M. T., Ge, Z., Jones, A. M., Ketchell, I., Gill, R. T., and Mahenthiralingam, E. (2008). Gene expression changes linked to antimicrobial resistance, oxidative stress, iron depletion and retained motility are observed when Burkholderia cenocepacia grows in cystic fibrosis sputum. BMC Infect. Dis. 8, 121. doi:10.1186/1471-2334-8-121

Engledow, A. S., Medrano, E. G., Mahenthiralingam, E., LiPuma, J. J., and Gonzalez, C. F. (2004). Involvement of a plasmid-encoded type IV secretion system in the plant tissue watersoaking phenotype of Burkholderia cenocepacia. J. Bacteriol. 186, 6015-6024.

Fehlner-Gardiner, C. C., Hopkins, T. M., and Valvano, M. A. (2002). Identification of a general secretory pathway in a human isolate of Burkholderia vietnamiensis (formerly B. cepacia complex genomovar V) that is required for the secretion of hemolysin and phospholipase C activities. Microb. Pathog. 32, 249-254.

Flannagan, R. S., Aubert, D., Kooi, C., Sokol, P. A., and Valvano, M. A. (2007). Burkholderia cenocepacia requires a periplasmic HtrA protease for growth under thermal and osmotic stress and for survival in vivo. Infect. Immun. 75, 1679-1689.

Gerdes, K., Christensen, S. K., and Lobner-Olesen, A. (2005). Prokaryotic toxin-antitoxin stress response loci. Nat. Rev. Microbiol. 3, 371-382.
Gingues, S., Kooi, C., Visser, M. B., Subsin, B., and Sokol, P. A. (2005). Distribution and expression of the ZmpA metalloprotease in the Burkholderia cepacia complex. J. Bacteriol. 187, 8247-8255.

Glendinning, K. J., Parsons, Y. N., Duangsonk, K., Hales, B. A., Humphreys, D., Hart, C. A., and Winstanley, C. (2004). Sequence divergence in type III secretion gene clusters of the Burkholderia cepacia complex. FEMS Microbiol. Lett. 235, 229-235.

Godlewska, R., Wisniewska, K., Pietras, Z., and Jagusztyn-Krynicka, E. K. (2009). Peptidoglycan-associated lipoprotein (Pal) of Gram-negative bacteria: function, structure, role in pathogenesis and potential application in immunoprophylaxis. FEMS Microbiol. Lett. 298, 1-11.

Hall, S. J., Hitchcock, A., Butler, C. S., and Kelly, D. J. (2008). A multicopper oxidase (Cj1516) and a CopA homologue (Cj1161) are major components of the copper homeostasis system of Campylobacter jejuni. J. Bacteriol. 190, 8075-8085.

Hellman, J., Roberts, J. D. Jr., Tehan, M. M., Allaire, J. E., and Warren, H. S. (2002). Bacterial peptidoglycanassociated lipoprotein is released into the bloodstream in Gramnegative sepsis and causes inflammation and death in mice. J. Biol. Chem. 277, 14274-14280.

Holden, M. T., Seth-Smith, H. M., Crossman, L. C., Sebaihia, M., Bentley, S. D., Cerdeno-Tarraga, A. M., Thomson, N. R., Bason, N., Quail, M. A., Sharp, S., Cherevach, I., Churcher, C., Goodhead, I., Hauser, H., Holroyd, N., Mungall, K., Scott, P., Walker, D., White, B., Rose, H., Iversen, P., Mil-Homens, D., Rocha, E. P., Fialho, A. M., Baldwin, A., Dowson, C., Barrell, B. G., Govan, J. R., Vandamme, P., Hart, C. A., Mahenthiralingam, E., and Parkhill, J. (2009). The genome of Burkholderia cenocepacia $\mathrm{J} 2315$, an epidemic pathogen of cystic fibrosis patients. J. Bacteriol. 191, 261-277.

Huber, B., Feldmann, F., Kothe, M., Vandamme, P., Wopperer, J., Riedel, 
K., and Eberl, L. (2004). Identification of a novel virulence factor in Burkholderia cenocepacia H111 required for efficient slow killing of Caenorhabditis elegans. Infect. Immun. 72, 7220-7230.

Hunt, T. A., Kooi, C., Sokol, P. A., and Valvano, M. A. (2004). Identification of Burkholderia cenocepacia genes required for bacterial survival in vivo. Infect. Immun. 72, 4010-4022.

Huston, W. M., Jennings, M. P., and McEwan, A. G. (2002). The multicopper oxidase of Pseudomonas aeruginosa is a ferroxidase with a central role in iron acquisition. Mol. Microbiol. 45, 1741-1750.

Inoue, T., Shingaki, R., Sogawa, N., Sogawa, C. A., Asaumi, J., Kokeguchi, S., and Fukui, K. (2003). Biofilm formation by a fimbriaedeficient mutant of Actinobacillus actinomycetemcomitans. Microbiol. Immunol. 47, 877-881.

Isles, A., Maclusky, I., Corey, M., Gold, R., Prober, C., Fleming, P., and Levison, H. (1984). Pseudomonas cepacia infection in cystic fibrosis: an emerging problem. J. Pediatr. 104, 206-210.

Jung, J. U., Gutierrez, C., Martin, F., Ardourel, M., and Villarejo, M. (1990). Transcription of osmB, a gene encoding an Escherichia coli lipoprotein, is regulated by dual signals. Osmotic stress and stationary phase. J. Biol. Chem. 265, 10574-10581.

Kachlany, S. C., Planet, P. J., Desalle, R., Fine, D. H., Figurski, D. H., and Kaplan, J. B. (2001). flp-1, the first representative of a new pilin gene subfamily, is required for nonspecific adherence of Actinobacillus actinomycetemcomitans. Mol. Microbiol. 40, 542-554.

Kim, H. S., Schell, M. A., Yu, Y., Ulrich, R. L., Sarria, S. H., Nierman, W. C., and Deshazer, D. (2005). Bacterial genome adaptation to niches: divergence of the potential virulence genes in three Burkholderia species of different survival strategies. BMC Genomics 6, 174. doi:10.1186/1471-2164-6-174

Koh, Y. S., and Roe, J. H. (1995). Isolation of a novel paraquat-inducible (pqi) gene regulated by the soxRS locus in Escherichia coli. J. Bacteriol. 177, 2673-2678.

Kooi, C., Subsin, B., Chen, R., Pohorelic, B., and Sokol, P. A. (2006). Burkholderia cenocepacia $\mathrm{ZmpB}$ is a broad-specificity zinc metalloprotease involved in virulence. Infect. Immun. 74, 4083-4093.

Kothe, M., Antl, M., Huber, B., Stoecker, K., Ebrecht, D., Steinmetz,
I., and Eberl, L. (2003). Killing of Caenorhabditis elegans by Burkholderia cepacia is controlled by the cep quorum-sensing system. Cell. Microbiol. 5, 343-351.

Krachler, A. M., Sharma, A., Cauldwell, A., Papadakos, G., and Kleanthous, C. (2010). TolA modulates the oligomeric status of $\mathrm{YbgF}$ in the bacterial periplasm. J. Mol. Biol. 403, 270-285.

Liang, M. D., Bagchi, A., Warren, H. S., Tehan, M. M., Trigilio, J. A., Beasley-Topliffe, L. K., Tesini, B. L., Lazzaroni, J. C., Fenton, M. J., and Hellman, J. (2005). Bacterial peptidoglycan-associated lipoprotein: a naturally occurring toll-like receptor 2 agonist that is shed into serum and has synergy with lipopolysaccharide. J. Infect. Dis. 191, 939-948.

LiPuma, J. J. (2010). The changing microbial epidemiology in cystic fibrosis. Clin. Microbiol. Rev. 23, 299-323.

Loutet, S. A., Flannagan, R. S., Kooi, C., Sokol, P. A., and Valvano, M. A. (2006). A complete lipopolysaccharide inner core oligosaccharide is required for resistance of Burkholderia cenocepacia to antimicrobial peptides and bacterial survival in vivo. J. Bacteriol. 188, 2073-2080.

Loutet, S. A., and Valvano, M. A. (2010). A decade of Burkholderia cenocepacia virulence determinant research. Infect. Immun. 78, 4088-4100.

Mahenthiralingam, E., Baldwin, A., and Dowson, C. G. (2008). Burkholderia cepacia complex bacteria: opportunistic pathogens with important natural biology. J. Appl. Microbiol. 104, 1539-1551.

Mahenthiralingam, E., Campbell, M. E., and Speert, D. P. (1994). Nonmotility and phagocytic resistance of Pseudomonas aeruginosa isolates from chronically colonized patients with cystic fibrosis. Infect. Immun. 62, 596-605.

Mahenthiralingam, E., Coenye, T., Chung, J. W., Speert, D. P., Govan, J. R., Taylor, P., and Vandamme, P. (2000). Diagnostically and experimentally useful panel of strains from the Burkholderia cepacia complex. J. Clin. Microbiol. 38, 910-913.

Mahenthiralingam, E., Urban, T. A., and Goldberg, J. B. (2005). The multifarious, multireplicon Burkholderia cepacia complex. Nat. Rev. Microbiol. 3, 144-156.

Makidon, P. E., Knowlton, J., Groom, J. V. II, Blanco, L. P., LiPuma, J. J., Bielinska, A. U., and Baker, J. R. Jr. (2010). Induction of immune response to the $17 \mathrm{kDa}$ OMPA
Burkholderia cenocepacia polypeptide and protection against pulmonary infection in mice after nasal vaccination with an OMP nanoemulsion-based vaccine. Med. Microbiol. Immunol. 199, 81-92.

Marolda, C. L., Hauroder, B., John, M. A., Michel, R., and Valvano, M. A. (1999). Intracellular survival and saprophytic growth of isolates from the Burkholderia cepacia complex in free-living amoebae. Microbiology 145(Pt 7), 1509-1517.

Mougous, J. D., Cuff, M. E., Raunser, S., Shen, A., Zhou, M., Gifford, C. A., Goodman, A. L., Joachimiak, G., Ordonez, C. L., Lory, S., Walz, T., Joachimiak, A., and Mekalanos, J. J. (2006). A virulence locus of Pseudomonas aeruginosa encodes a protein secretion apparatus. Science 312, 1526-1530.

Munoz-Elias, E. J., and McKinney, J. D. (2005). Mycobacterium tuberculosis isocitrate lyases 1 and 2 are jointly required for in vivo growth and virulence. Nat. Med. 11, 638-644.

Munoz-Elias, E. J., Upton, A. M., Cherian, J., and McKinney, J. D. (2006). Role of the methylcitrate cycle in Mycobacterium tuberculosis metabolism, intracellular growth, and virulence. Mol. Microbiol. 60, 1109-1122.

Mutschler, H., Gebhardt, M., Shoeman, R. L., and Meinhart, A. (2011). A novel mechanism of programmed cell death in bacteria by toxin-antitoxin systems corrupts peptidoglycan synthesis. PLoS Biol. 9, e1001033. doi:10.1371/journal.pbio. 1001033

O'Grady, E. P., Nguyen, D. T., Weisskopf, L., Eberl, L., and Sokol, P. A. (2011). The Burkholderia cenocepacia LysR-type transcriptional regulator ShvR influences expression of quorum-sensing, protease, type II secretion, and afc genes. J. Bacteriol. 193, 163-176.

O'Grady, E. P., Viteri, D. F., Malott, R. J., and Sokol, P. A. (2009). Reciprocal regulation by the CepIR and CcilR quorum sensing systems in Burkholderia cenocepacia. BMC Genomics 10, 441. doi:10.1186/1471-2164-10-441

Paterson, G. K., Northen, H., Cone, D. B., Willers, C., Peters, S. E., and Maskell, D. J. (2009). Deletion of tolA in Salmonella typhimurium generates an attenuated strain with vaccine potential. Microbiology 155, 220-228.

Peeters, E., Sass, A., Mahenthiralingam, E., Nelis, H., and Coenye, T. (2010). Transcriptional response of Burkholderia cenocepacia J2315 sessile cells to treatments with high doses of hydrogen peroxide and sodium hypochlorite. BMC Genomics 11, 90 . doi:10.1186/1471-2164-11-90

Potter, A. J., Kidd, S. P., Edwards, J. L., Falsetta, M. L., Apicella, M. A., Jennings, M. P., and McEwan, A. G. (2009). Thioredoxin reductase is essential for protection of Neisseria gonorrhoeae against killing by nitric oxide and for bacterial growth during interaction with cervical epithelial cells. J. Infect. Dis. 199, 227-235.

Rozen, S., and Skaletsky, H. (2000). Primer3 on the WWW for general users and for biologist programmers. Methods Mol. Biol. 132, 365-386.

Sajjan, S. U., Carmody, L. A., Gonzalez, C. F., and LiPuma, J. J. (2008). A type IV secretion system contributes to intracellular survival and replication of Burkholderia cenocepacia. Infect. Immun. 76, 5447-5455.

Sass, A., Marchbank, A., Tullis, E., Lipuma, J. J., and Mahenthiralingam, E. (2011). Spontaneous and evolutionary changes in the antibiotic resistance of Burkholderia cenocepacia observed by global gene expression analysis. BMC Genomics 12, 373 doi:10.1186/1471-2164-12-373

Schmittgen, T. D., and Livak, K. J. (2008). Analyzing real-time PCR data by the comparative $\mathrm{C}(\mathrm{T})$ method. Nat. Protoc. 3, 1101-1108.

Schnappinger, D., Ehrt, S., Voskuil, M. I., Liu, Y., Mangan, J. A., Monahan, I. M., Dolganov, G., Efron, B., Butcher, P. D., Nathan, C., and Schoolnik, G. K. (2003). Transcriptional adaptation of Mycobacterium tuberculosis within macrophages: insights into the phagosomal environment. J. Exp. Med. 198, 693-704.

Seed, K. D., and Dennis, J. J. (2008). Development of Galleria mellonella as an alternative infection model for the Burkholderia cepacia complex. Infect. Immun. 76, 1267-1275.

Sisinni, L., Cendron, L., Favaro, G., and Zanotti, G. (2010). Helicobacter pylori acidic stress response factor HP1286 is a YceI homolog with new binding specificity. FEBS J. 277, 1896-1905.

Smith, A. W., Roche, H., Trombe, M. C., Briles, D. E., and Hakansson, A. (2002). Characterization of the dihydrolipoamide dehydrogenase from Streptococcus pneumoniae and its role in pneumococcal infection. Mol. Microbiol. 44, 431-448.

Sokol, P. A., Darling, P., Lewenza, S., Corbett, C. R., and Kooi, C. D. (2000). Identification of a siderophore receptor required for ferric ornibactin uptake in Burkholderia cepacia. Infect. Immun. 68, 6554-6560. 
Sokol, P. A., Darling, P., Woods, D. E., Mahenthiralingam, E., and Kooi, C. (1999). Role of ornibactin biosynthesis in the virulence of Burkholderia cepacia: characterization of pvdA, the gene encoding LOrnithine N5 -oxygenase. Infect. Immun. 67, 4443-4455.

Sokol, P. A., Sajjan, U., Visser, M. B., Gingues, S., Forstner, J., and Kooi, C. (2003). The CepIR quorum-sensing system contributes to the virulence of Burkholderia cenocepacia respiratory infections. Microbiology 149, 3649-3658.

Somvanshi, V. S., Viswanathan, P., Jacobs, J. L., Mulks, M. H., Sundin, G. W., and Ciche, T. A. (2010). The type 2 secretion pseudopilin, gspJ, is required for multihost pathogenicity of Burkholderia cenocepacia AU1054. Infect. Immun. 78, 4110-4121.

Subramoni, S., Nguyen, D. T., and Sokol, P. A. (2011). Burkholderia cenocepacia ShvR-regulated genes that influence colony morphology, biofilm formation, and virulence. Infect. Immun. 79, 2984-2997.

Tomich, M., Griffith, A., Herfst, C. A., Burns, J. L., and Mohr, C. D. (2003). Attenuated virulence of a Burkholderia cepacia type III secretion mutant in a murine model of infection. Infect. Immun. 71, 1405-1415.

Tomich, M., Herfst, C. A., Golden, J. W., and Mohr, C. D. (2002). Role of flagella in host cell invasion by Burkholderia cepacia. Infect. Immun. 70, 1799-1806.

Tuanyok, A., Tom, M., Dunbar, J., and Woods, D. E. (2006). Genome-wide expression analysis of Burkholderia pseudomallei infection in a hamster model of acute melioidosis. Infect. Immun. 74, 5465-5476.

Uehlinger, S., Schwager, S., Bernier, S. P., Riedel, K., Nguyen, D. T., Sokol, P. A., and Eberl, L. (2009). Identification of specific and universal virulence factors in Burkholderia cenocepacia strains by using multiple infection hosts. Infect. Immun. 77, 4102-4110.

Urban, T. A., Griffith, A., Torok, A. M., Smolkin, M. E., Burns, J. L., and Goldberg, J. B. (2004). Contribution of Burkholderia cenocepacia flagella to infectivity and inflammation. Infect. Immun. 72, 5126-5134.

Van Melderen, L., and Saavedra De Bast, M. (2009). Bacterial toxinantitoxin systems: more than selfish entities? PLoS Genet. 5, e1000437. doi:10.1371/journal.pgen.1000437

Velasco-Garcia, R., Villalobos, M. A., Ramirez-Romero, M. A., Mujica-Jimenez, C., Iturriaga, G., and Munoz-Clares, R. A. (2006a). Betaine aldehyde dehydrogenase from Pseudomonas aeruginosa: cloning, over-expression in Escherichia coli, and regulation by choline and salt. Arch. Microbiol. 185, 14-22.

Velasco-Garcia, R., Zaldivar-Machorro, V. J., Mujica-Jimenez, C., GonzalezSegura, L., and Munoz-Clares, R. A. (2006b). Disulfiram irreversibly aggregates betaine aldehyde dehydrogenase - a potential target for antimicrobial agents against Pseudomonas aeruginosa. Biochem. Biophys. Res. Commun. 341, 408-415.

Vergunst, A. C., Meijer, A. H., Renshaw, S. A., and O'Callaghan, D. (2010). Burkholderia cenocepacia creates an intramacrophage replication niche in zebrafish embryos, followed by bacterial dissemination and establishment of systemic infection. Infect. Immun. 78, 1495-1508.

Visser, M. B., Majumdar, S., Hani, E., and Sokol, P. A. (2004). Importance of the ornibactin and pyochelin siderophore transport systems in Burkholderia cenocepacia lung infections. Infect. Immun. 72, 2850-2857.

Weber, A., Kogl, S. A., and Jung, K. (2006). Time-dependent proteome alterations under osmotic stress during aerobic and anaerobic growth in Escherichia coli. J. Bacteriol. 188, 7165-7175.

Weingart, C. L., White, C. E., Liu, S. Chai, Y., Cho, H., Tsai, C. S., Wei, Y., Delay, N. R., Gronquist, M. R., Eberhard, A., and Winans, S. C. (2005). Direct binding of the quorum sensing regulator CepR of Burkholderia cenocepacia to two target promoters in vitro. Mol. Microbiol. 57, 452-467.

Werner, J., and Misra, R. (2005). YaeT (Omp85) affects the assembly of lipid-dependent and lipidindependent outer membrane proteins of Escherichia coli. Mol. Microbiol. 57, 1450-1459.

Winsor, G. L., Khaira, B., Van Rossum, T., Lo, R., Whiteside, M. D., and Brinkman, F. S. (2008). The Burkholderia Genome Database: facilitating flexible queries and comparative analyses. Bioinformatics 24 2803-2804.

Wolfgang, M. C., Jyot, J., Goodman, A. L., Ramphal, R., and Lory, S. (2004). Pseudomonas aeruginosa regulates flagellin expression as part of a global response to airway fluid from cystic fibrosis patients. Proc. Natl. Acad. Sci. U.S.A. 101, 6664-6668.

Wright, J. R., and Clements, J. A. (1987) Metabolism and turnover of lung surfactant. Am. Rev. Respir. Dis. 136, 426-444.

Yoder-Himes, D. R., Chain, P. S., Zhu, Y., Wurtzel, O., Rubin, E. M., Tiedje, J. M., and Sorek, R. (2009). Mapping the Burkholderia cenocepacia niche response via high-throughput sequencing.
Proc. Natl. Acad. Sci. U.S.A. 106, 3976-3981.

Yoder-Himes, D. R., Konstantinidis, K. T., and Tiedje, J. M. (2010). Identification of potential therapeutic targets for Burkholderia cenocepacia by comparative transcriptomics. PLoS ONE 5, e8724. doi:10.1371/journal.pone.0008724

Zaldivar-Machorro, V. J., Lopez-Ortiz, M., Demare, P., Regla, I., and Munoz-Clares, R. A. (2011). The disulfiram metabolites $S$-methyl$N, N$-diethyldithiocarbamoyl sulfoxide and $S$-methyl-N,Ndiethylthiocarbamoyl sulfone irreversibly inactivate betaine aldehyde dehydrogenase from Pseudomonas aeruginosa, both in vitro and in situ, and arrest bacterial growth. Biochimie 93, 286-295.

Conflict of Interest Statement: The authors declare that the research was conducted in the absence of any commercial or financial relationships that could be construed as a potential conflict of interest.

Received: 30 August 2011; accepted: 20 November 2011; published online: 09 December 2011.

Citation: O'Grady EP and Sokol PA (2011) Burkholderia cenocepacia differential gene expression during host-pathogen interactions and adaptation to the host environment. Front. Cell. Inf. Microbio. 1:15. doi: 10.3389/fcimb.2011.00015

Copyright (c) 2011 O'Grady and Sokol. This is an open-access article distributed under the terms of the Creative Commons Attribution Non Commercial License, which permits non-commercial use, distribution, and reproduction in other forums, provided the original authors and source are credited. 


\section{APPENDIX}

Table A1 | Burkholderia cenocepacia genes induced during chronic lung infection.

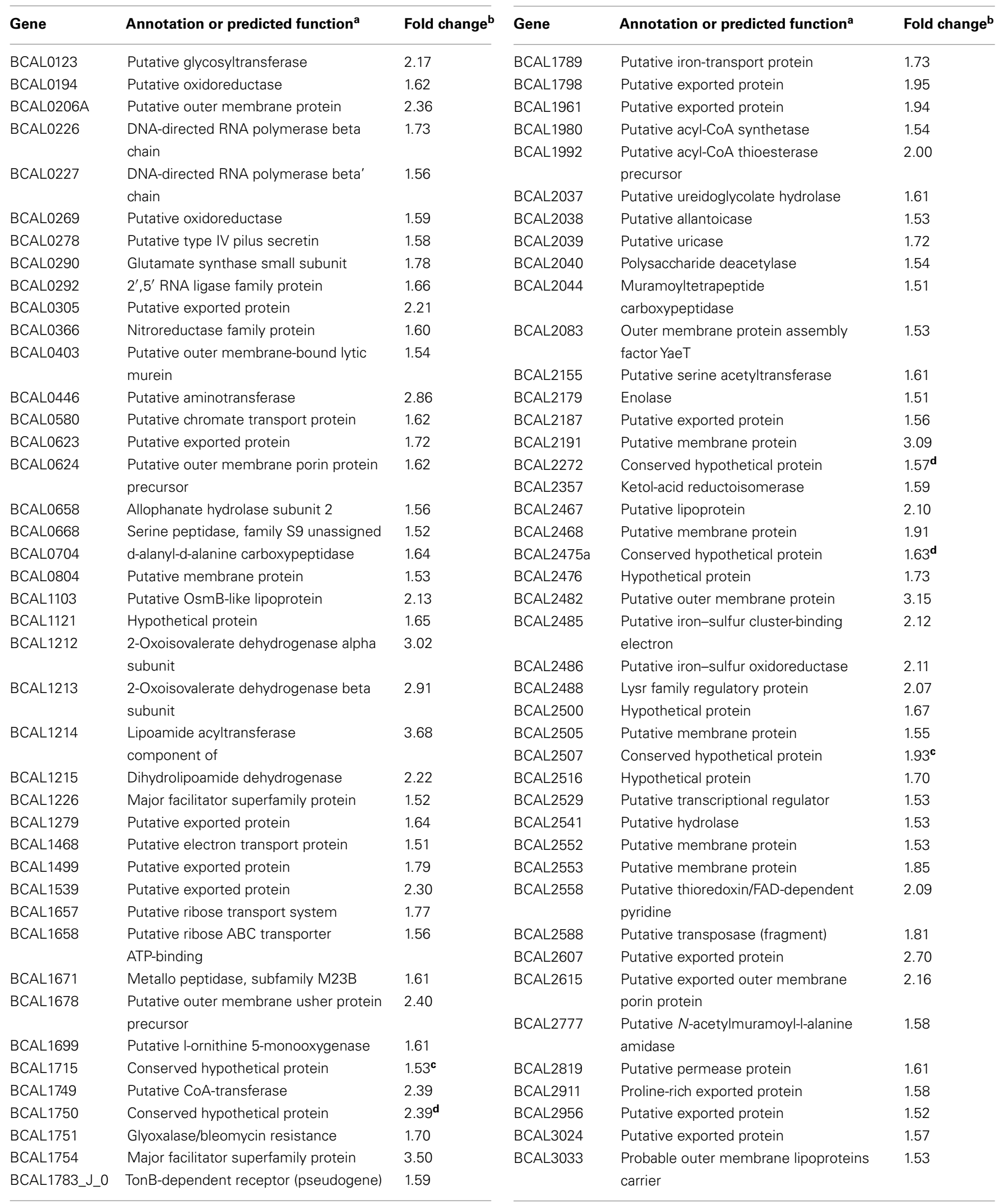


Table A1 | Continued

\begin{tabular}{|c|c|c|c|c|c|}
\hline Gene & Annotation or predicted function ${ }^{a}$ & Fold change $^{b}$ & Gene & Annotation or predicted function ${ }^{a}$ & Fold change $^{b}$ \\
\hline & component & & BCAM0595 & LysR family regulatory protein & 2.56 \\
\hline BCAL3040 & $\mathrm{ABC}$ transporter, membrane permease & 1.71 & BCAM0676 & Putative exported protein & 1.84 \\
\hline BCAL3041 & Maltose-binding protein & 2.09 & BCAM0880 & Putative methyltransferase & 7.10 \\
\hline BCAL3163 & Putative nucleotidyltransferase & 1.68 & BCAM0895 & Conserved hypothetical protein & $1.55^{\mathbf{c}}$ \\
\hline BCAL3204 & Putative OmpA family lipoprotein & 1.68 & BCAM0926 & $\begin{array}{l}\text { Multidrug efflux system transporter } \\
\text { protein }\end{array}$ & 5.89 \\
\hline BCAL3205 & Putative exported protein & 1.62 & BCAM0944 & Putative lipoprotein & 1.58 \\
\hline BCAL3289 & Putative glycolate oxidase subunit GlcE & 1.64 & \multirow[t]{2}{*}{ BCAM0983 } & \multirow{2}{*}{$\begin{array}{l}\text { 3-Isopropylmalate dehydratase large } \\
\text { subunit }\end{array}$} & \multirow[t]{2}{*}{2.87} \\
\hline BCAL3297 & Putative ferritin DPS-family & 1.67 & & & \\
\hline & DNA-binding & & BCAM0983A & $\begin{array}{l}\text { Putative entericidin B-like bacteriolytic } \\
\text { toxin }\end{array}$ & 2.01 \\
\hline BCAL3364 & Putative gluconokinase & 1.66 & BCAM1016 & Putative ribonuclease & 1.81 \\
\hline BCAL3473 & Putative outer membrane porin & 1.87 & BCAM1053 & Putative reverse transcriptase - Group & 1.72 \\
\hline \multirow[t]{2}{*}{ BCAL3486 } & \multirow{2}{*}{$\begin{array}{l}\text { Putative RNA polymerase sigma factor, } \\
\text { sigma-70 }\end{array}$} & \multirow[t]{2}{*}{1.84} & & $\|$ & \\
\hline & & & BCAM1150 & 3-Hydroxyisobutyrate dehydrogenase & 1.64 \\
\hline BCAL3490 & Putative exported protein & 1.96 & \multirow[t]{2}{*}{ BCAM1151 } & \multirow{2}{*}{$\begin{array}{l}\text { Methylmalonate-semialdehyde } \\
\text { dehydrogenase }\end{array}$} & \multirow[t]{2}{*}{2.40} \\
\hline BCAL3492 & Putative exported protein & 1.63 & & & \\
\hline BCAM0027 & PadR family regulatory protein & 1.51 & BCAM1171 & Major facilitator superfamily protein & 1.55 \\
\hline BCAM0042 & Putative aldo/keto reductase & 1.75 & BCAM1187 & TonB-dependent siderophore receptor & 1.71 \\
\hline BCAM0047 & Putative transporter - LysE family & 2.57 & \multirow[t]{2}{*}{ BCAM1207 } & \multirow{2}{*}{$\begin{array}{l}\text { ABC transporter ATP-binding } \\
\text { membrane protein }\end{array}$} & 1.52 \\
\hline BCAM0094 & Xylulose kinase & 1.67 & & & \\
\hline BCAM0126 & Putative AMP-binding enzyme & 1.65 & BCAM1263 & Putative malate/l-lactate & 1.79 \\
\hline BCAM0271 & Conserved hypothetical protein & $1.66^{\mathbf{d}}$ & BCAM1341 & Conserved hypothetical protein & $3.22^{\mathrm{c}}$ \\
\hline BCAM0273 & Conserved hypothetical protein & $2.08^{\mathrm{d}}$ & BCAM1374 & Conserved hypothetical protein & $1.87^{\mathrm{c}}$ \\
\hline BCAM0274a & Hypothetical protein & 1.95 & BCAM1390 & Putative aldolase & 3.00 \\
\hline BCAM0275 & Conserved hypothetical protein & $1.60^{d}$ & BCAM1425 & Putative membrane protein & 2.88 \\
\hline BCAM0275a & Conserved hypothetical protein & $1.70^{\mathbf{d}}$ & BCAM1427 & LysE family transporter & 3.76 \\
\hline BCAM0277 & Conserved hypothetical protein & $1.72^{\mathbf{c}}$ & BCAM1487 & Putative $A B C$ transporter, & 3.14 \\
\hline BCAM0303 & ABC transporter ATP-binding & 1.62 & & substrate-binding & \\
\hline & membrane protein & & BCAM1488 & Putative proline racemase & 1.90 \\
\hline BCAM0368 & Putative branched-chain amino acid & 1.52 & BCAM1527 & Putative cation efflux protein & 1.82 \\
\hline & transport & & BCAM1563 & ABC transporter ATP-binding & 1.70 \\
\hline BCAM0414 & Conserved hypothetical protein & $2.01^{\mathrm{d}}$ & & membrane protein & \\
\hline BCAM0415 & $\begin{array}{l}\text { Putative betaine aldehyde } \\
\text { dehydrogenase }\end{array}$ & 1.53 & BCAM1679 & $\begin{array}{l}\text { Putative lysylphosphatidylglycerol } \\
\text { synthetase }\end{array}$ & 1.62 \\
\hline BCAM0422 & LuxR superfamily regulatory protein & 1.89 & BCAM1726 & Putative exported protein & 2.01 \\
\hline BCAM0447 & Putative exported multicopper oxidase & 13.01 & BCAM1742 & Putative exported protein & 1.87 \\
\hline BCAM0459 & Cysteine desulfurase & 3.60 & BCAM1775 & Putative transglycosylase associated & 1.76 \\
\hline BCAM0478 & Glucosamine - fructose-6-phosphate & 1.52 & & protein & \\
\hline
\end{tabular}


Table A1 | Continued

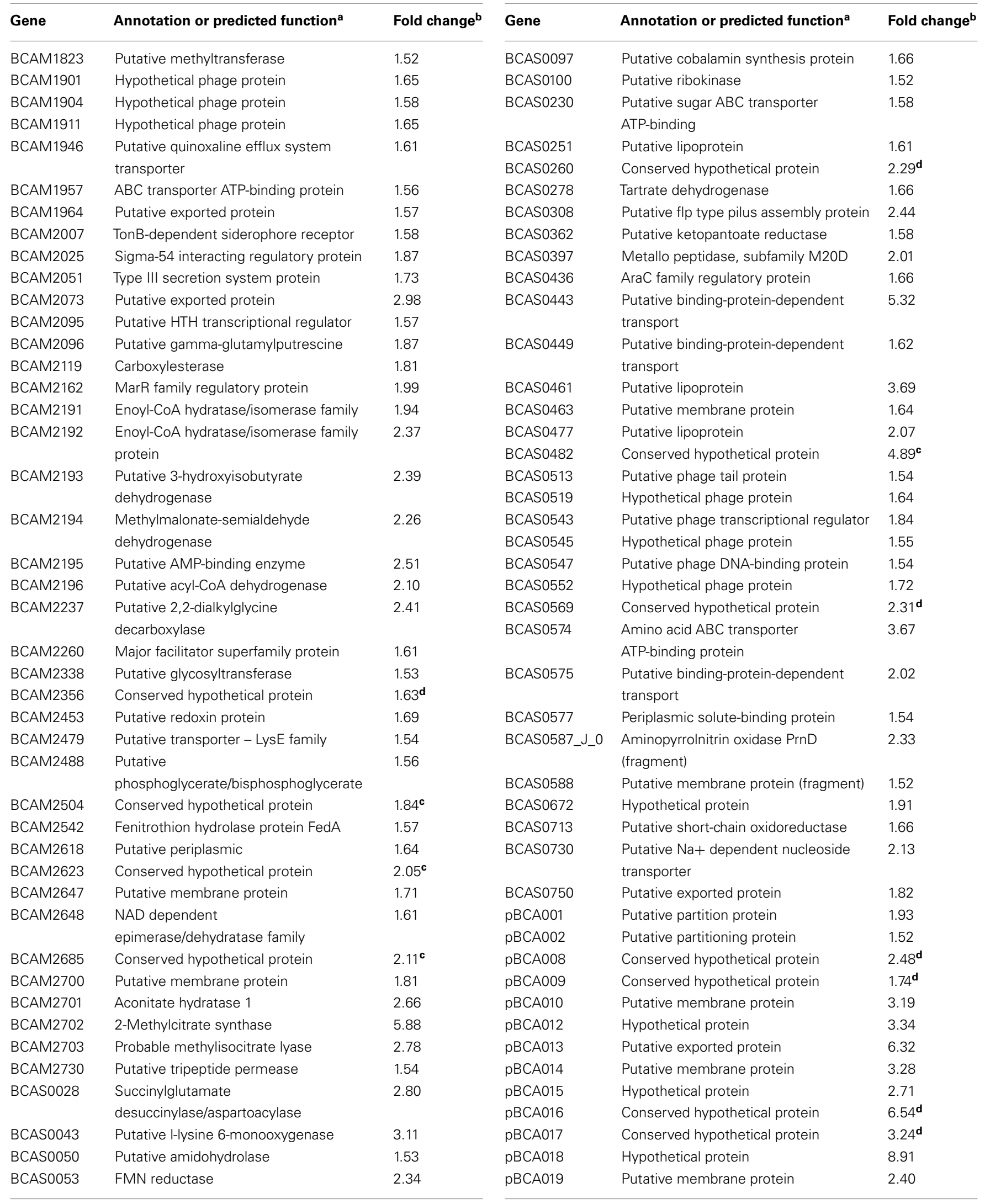


Table A1 | Continued

\begin{tabular}{|c|c|c|}
\hline Gene & Annotation or predicted function ${ }^{a}$ & Fold change ${ }^{b}$ \\
\hline pBCA020 & $\begin{array}{l}\text { Putative TraG conjugative transfer } \\
\text { protein }\end{array}$ & 5.51 \\
\hline pBCA021 & $\begin{array}{l}\text { Putative TraH conjugative transfer } \\
\text { protein }\end{array}$ & 13.21 \\
\hline pBCA022 & Conserved hypothetical protein & $8.09^{c}$ \\
\hline pBCA023 & Conserved hypothetical protein & $5.09^{d}$ \\
\hline pBCA024 & Conserved hypothetical protein & $10.16^{\mathbf{c}}$ \\
\hline pBCA025 & $\begin{array}{l}\text { Putative TraF conjugative transfer } \\
\text { protein }\end{array}$ & 7.10 \\
\hline pBCA026 & Putative membrane protein & 10.57 \\
\hline pBCA027 & $\begin{array}{l}\text { Putative conjugative transfer protein } \\
\text { TraN }\end{array}$ & 14.73 \\
\hline pBCA028 & Conserved hypothetical protein & $5.03^{d}$ \\
\hline pBCA029 & Putative membrane protein & 8.60 \\
\hline pBCA030 & $\begin{array}{l}\text { Putative conjugative transfer protein } \\
\text { TrbC }\end{array}$ & 6.06 \\
\hline pBCA031 & $\begin{array}{l}\text { Putative TraU conjugative transfer } \\
\text { protein }\end{array}$ & 6.92 \\
\hline pBCA032 & $\begin{array}{l}\text { Putative TraW conjugative transfer } \\
\text { protein }\end{array}$ & 8.96 \\
\hline pBCA033 & Putative peptidase protein & 4.97 \\
\hline pBCA034 & Putative membrane protein & 6.01 \\
\hline pBCA035 & GntR family regulatory protein & 18.91 \\
\hline pBCA036 & Putative membrane protein & 13.82 \\
\hline pBCA037 & Putative membrane protein & 7.33 \\
\hline pBCA037a & Hypothetical protein & 11.90 \\
\hline pBCA038 & Hypothetical protein & 9.54 \\
\hline pBCA039 & Hypothetical protein & 1.98 \\
\hline pBCA040 & Hypothetical protein & 2.04 \\
\hline pBCA041 & $\begin{array}{l}\text { Putative TraC conjugative transfer } \\
\text { protein }\end{array}$ & 9.20 \\
\hline pBCA042 & Type IV secretion system TraV & 19.71 \\
\hline pBCA043 & $\begin{array}{l}\text { Thiol:disulfide interchange protein } \\
\text { DsbC }\end{array}$ & 7.91 \\
\hline pBCA044 & $\begin{array}{l}\text { Putative TraB conjugative transfer } \\
\text { protein }\end{array}$ & 3.00 \\
\hline
\end{tabular}

\begin{tabular}{|c|c|c|}
\hline Gene & Annotation or predicted function ${ }^{a}$ & Fold change ${ }^{b}$ \\
\hline pBCA045 & Putative exported protein TraK & 12.43 \\
\hline pBCA046 & $\begin{array}{l}\text { Putative TraE conjugative transfer } \\
\text { protein }\end{array}$ & 16.87 \\
\hline pBCA047 & $\begin{array}{l}\text { Type IV conjugative transfer system } \\
\text { protein TraL }\end{array}$ & 46.07 \\
\hline pBCA048 & Putative membrane protein & 55.79 \\
\hline pBCA049 & Putative transglycosylase protein & 4.97 \\
\hline pBCA050 & Hypothetical protein & 8.74 \\
\hline pBCA051 & LamB/YcsF family protein & 159.40 \\
\hline pBCA052 & Putative exported protein & 789.20 \\
\hline pBCA053 & $\begin{array}{l}\text { Putative extracellular solute-binding } \\
\text { protein }\end{array}$ & 480.70 \\
\hline pBCA054 & LuxR family regulatory protein & 3.90 \\
\hline pBCA056 & Hypothetical protein & 4.34 \\
\hline pBCA057 & Putative conjugative transfer protein & 4.80 \\
\hline pBCA058 & $\begin{array}{l}\text { Thiol:disulfide interchange protein } \\
\text { DsbD }\end{array}$ & 7.43 \\
\hline pBCA059 & $\begin{array}{l}\text { Putative TraD conjugative transfer } \\
\text { protein }\end{array}$ & 4.13 \\
\hline pBCA060 & Hypothetical protein & 6.97 \\
\hline pBCA062 & Conserved hypothetical protein & $2.52^{d}$ \\
\hline pBCA065 & Conserved hypothetical protein & $1.53^{\mathbf{c}}$ \\
\hline pBCA076 & Conserved hypothetical protein & $1.55^{\mathbf{c}}$ \\
\hline pBCA077 & Conserved hypothetical protein & $1.66^{\mathbf{d}}$ \\
\hline pBCA087 & NUDIX hydrolase family protein & 1.53 \\
\hline pBCA088 & Amidohydrolase family protein & 1.64 \\
\hline pBCA090 & Putative integrase & 1.68 \\
\hline pBCA095 & Putative ligase & 1.59 \\
\hline
\end{tabular}

a Derived from B. cenocepacia J2315 (Holden et al., 2009) at http://Www. burkholderia.com (Winsor et al., 2008) or http://www.microbesonline.org (Dehal et al., 2009).

${ }^{b}$ Fold change of RNA recovered from rat lungs (in vivo) relative to RNA isolated from in vitro grown cultures as determined by microarray analysis.

${ }^{\circ}$ Conserved hypothetical protein in one or more members of the Bcc and in B. pseudomallei.

${ }^{d}$ Conserved hypothetical protein in one or more members of the Bcc. 
Table A2 | Burkholderia cenocepacia genes induced during culture in vitro.

\begin{tabular}{|c|c|c|c|c|c|}
\hline Gene & Annotation or predicted function ${ }^{a}$ & Fold change ${ }^{b}$ & Gene & Annotation or predicted function ${ }^{a}$ & Fold change $^{b}$ \\
\hline BCAL0046 & Putative fatty-acid CoA ligase & 1.56 & BCAL0514 & Putative membrane protein & 2.52 \\
\hline BCAL0057 & Putative membrane protein & 2.17 & BCAL0522 & Flagellum-specific ATP synthase Flil & 1.84 \\
\hline BCAL0112 & Conserved hypothetical protein & 1.82 & BCAL0523 & Flagellar assembly protein $\mathrm{FliH}$ & 1.63 \\
\hline \multirow[t]{2}{*}{ BCAL0113 } & B-type flagellar hook-associated & 2.71 & BCAL0527 & Flagellar protein FliS & 3.38 \\
\hline & protein 2 & & BCAL0528 & Conserved hypothetical protein & 2.80 \\
\hline BCAL0114 & Flagellin (type II) & 8.29 & BCAL0543 & Major facilitator superfamily protein & 1.64 \\
\hline BCAL0121 & Aquaporin Z & 3.29 & BCAL0561 & Flagella synthesis protein FlgN & 1.94 \\
\hline BCAL0126 & Chemotaxis protein MotA & 2.19 & BCAL0562 & Negative regulator of flagellin synthesis & 2.56 \\
\hline BCAL0127 & Chemotaxis protein MotB & 2.03 & BCAL0567 & Flagellar hook protein 1 FlgE1 & 1.57 \\
\hline BCAL0128 & $\begin{array}{l}\text { Chemotaxis two-component response } \\
\text { regulator }\end{array}$ & 2.96 & BCAL0568 & $\begin{array}{l}\text { Flagellar basal-body rod protein FlgF } \\
\text { (putative }\end{array}$ & 1.66 \\
\hline BCAL0129 & $\begin{array}{l}\text { Chemotaxis two-component sensor } \\
\text { kinase CheA }\end{array}$ & 2.38 & BCAL0576 & $\begin{array}{l}\text { Flagellar hook-associated protein } 1 \\
\text { (HAP1) }\end{array}$ & 3.18 \\
\hline BCAL0130 & Chemotaxis protein CheW & 1.63 & BCAL0577 & Flagellar hook-associated protein 3 & 3.20 \\
\hline BCAL0132 & Chemotaxis protein methyltransferase & 2.52 & & (HAP3) & \\
\hline BCAL0133 & $\begin{array}{l}\text { Putative chemoreceptor glutamine } \\
\text { deamidase cheD }\end{array}$ & 2.47 & BCAL0621 & $\begin{array}{l}\text { Putative cyclic-di-GMP signaling } \\
\text { protein }\end{array}$ & 1.56 \\
\hline \multirow[t]{2}{*}{ BCAL0134 } & Chemotaxis response regulator & 2.04 & BCAL0705 & Putative d-amino acid aminotransferase & 1.55 \\
\hline & protein-glutamate & & BCAL0706 & Conserved hypothetical protein & 1.75 \\
\hline BCAL0135 & Chemotaxis protein $\mathrm{CheY}$ & 1.52 & BCAL0744 & Appr-1-p processing enzyme family & 1.74 \\
\hline BCAL0136 & Chemotaxis protein CheZ & 2.09 & & protein & \\
\hline BCAL0140 & Flagellar biosynthetic protein FlhB & 2.46 & BCAL0771 & Non-heme chloroperoxidase & 1.82 \\
\hline BCAL0143 & Putative flagellar biosynthesis protein & 1.71 & BCAL0808 & P-loop ATPase protein family protein & 1.88 \\
\hline \multirow[t]{2}{*}{ BCAL0147 } & 5,10-Methylenetetrahydrofolate & 2.17 & BCAL0812 & Sigma-54 modulation protein & 1.91 \\
\hline & reductase & & BCAL0813 & Putative RNA polymerase sigma-54 & 2.13 \\
\hline BCAL0154 & Histone-like nucleoid-structuring (H-NS) & 1.97 & & factor & \\
\hline BCAL0168 & Hypothetical protein & 2.50 & BCAL0831 & Putative storage protein & 4.32 \\
\hline BCAL0169 & Conserved hypothetical protein & 2.42 & BCAL0833 & Putative Acetoacetyl-CoA reductase & 1.78 \\
\hline BCAL0179 & Hypothetical protein & 1.87 & BCAL0834 & Putative membrane protein & 2.15 \\
\hline \multirow[t]{2}{*}{ BCAL0203 } & Phosphatidylethanolamine-binding & 1.56 & BCAL0842 & Putative membrane protein & 2.26 \\
\hline & protein & & BCAL0928 & Conserved hypothetical protein & 3.58 \\
\hline \multirow[t]{2}{*}{ BCAL0212 } & Putative phenylacetic acid degradation & 1.63 & BCAL0947 & Putative membrane protein & 1.55 \\
\hline & NADH & & BCAL1055 & Histidine transport system permease & 1.74 \\
\hline BCAL0233 & 30s Ribosomal protein S10 & 1.59 & & protein & \\
\hline BCAL0339 & Putative lipoprotein & 1.60 & BCAL1056 & Histidine transport system permease & 1.81 \\
\hline BCAL0341 & Conserved hypothetical protein & 1.75 & & protein & \\
\hline BCAL0342 & Conserved hypothetical protein & 1.68 & BCAL1057 & Histidine ABC transporter ATP-binding & 1.98 \\
\hline BCAL0343 & Conserved hypothetical protein & 1.86 & & protein & \\
\hline BCAL0344 & Conserved hypothetical protein & 1.58 & BCAL1058 & AraC family regulatory protein & 2.22 \\
\hline BCAL0345 & Conserved hypothetical protein & 1.78 & BCAL1059 & Succinylornithine transaminase & 1.81 \\
\hline BCAL0356 & Putative quinone oxidoreductase & 1.51 & BCAL1060 & Putative arginine & 1.63 \\
\hline BCAL0404 & Phenylacetate-coenzyme A ligase & 1.59 & & $N$-succinyltransferase, alpha & \\
\hline BCAL0406 & Probable enoyl-CoA hydratase PaaG & 1.56 & BCAL1061 & Putative arginine & 1.86 \\
\hline \multirow[t]{2}{*}{ BCAL0412 } & Conserved hypothetical protein & 2.11 & & N-succinyltransferase, beta & \\
\hline & (pseudogene) & & BCAL1062 & Succinylglutamic semialdehyde & 1.90 \\
\hline BCAL0413 & Conserved hypothetical protein & 1.67 & & dehydrogenase & \\
\hline BCAL0431 & Conserved hypothetical protein & 1.86 & BCAL1063 & Succinylarginine dihydrolase & 2.58 \\
\hline BCAL0432 & Putative membrane protein & 1.61 & BCAL1064 & Putative succinylglutamate & 2.00 \\
\hline BCAL0434 & Putative exported protein & 2.13 & & desuccinylase & \\
\hline BCAL0505 & Integrase/recombinase & 1.71 & BCAL1065 & Periplasmic solute-binding protein & 1.91 \\
\hline BCAL0511 & Putative deoxygenases & 1.60 & BCAL1146 & AraC family regulatory protein & 1.73 \\
\hline
\end{tabular}


Table A2 | Continued

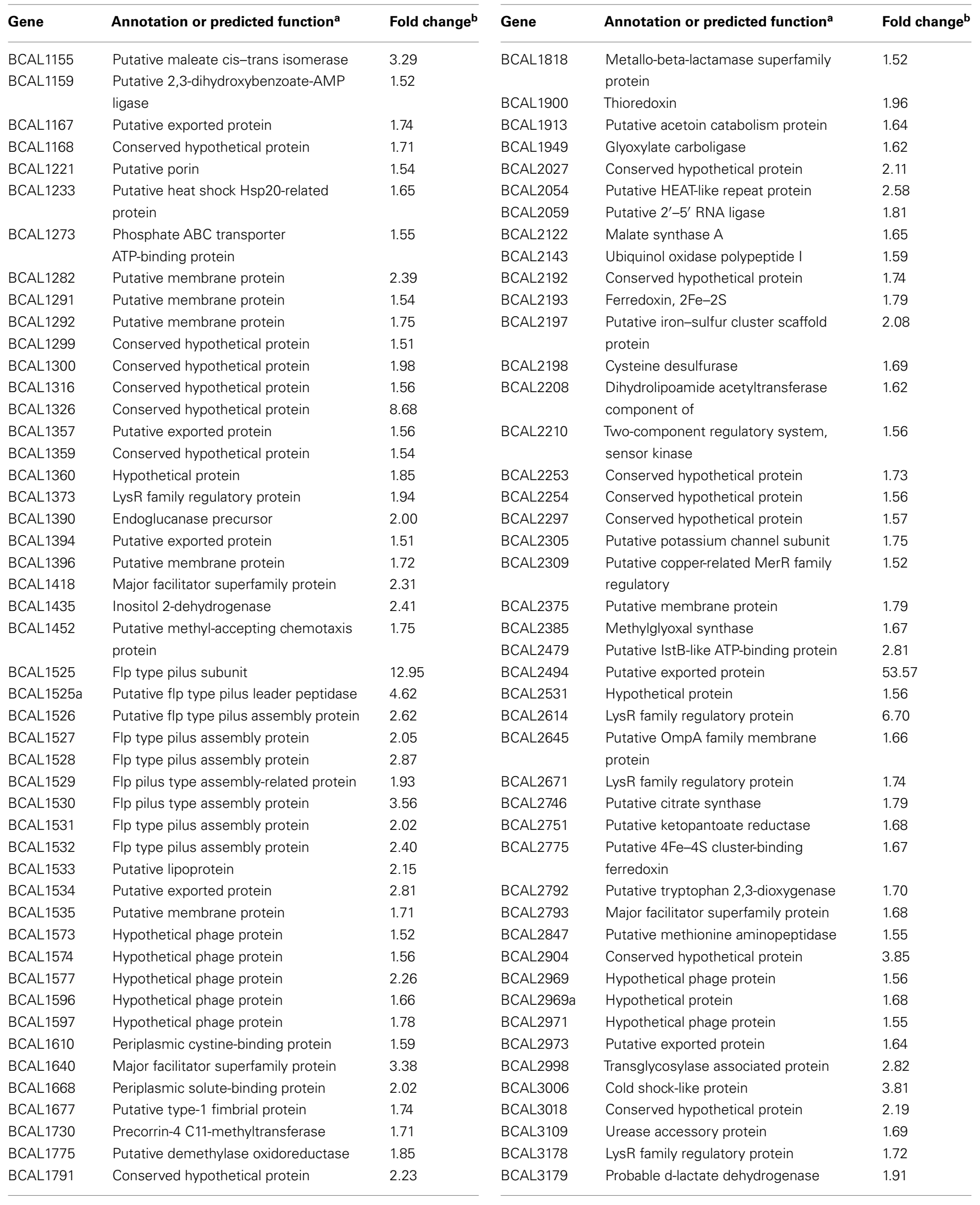


Table A2 | Continued

\begin{tabular}{|c|c|c|c|c|c|}
\hline Gene & Annotation or predicted function ${ }^{a}$ & Fold change $^{b}$ & Gene & Annotation or predicted function ${ }^{a}$ & Fold change ${ }^{b}$ \\
\hline BCAL3227 & Conserved hypothetical protein & 2.10 & BCAM0917 & Putative DNA primase & 1.64 \\
\hline BCAL3234 & Glycosyltransferase & 1.69 & BCAM0942 & Putative exported protein & 1.59 \\
\hline BCAL3239 & Glucosyltransferase & 1.84 & BCAM0953 & Extracellular solute-binding protein & 1.80 \\
\hline BCAL3368 & Putative regulatory protein & 1.85 & BCAM0957 & Putative pepstatin-insensitive carboxyl & 1.64 \\
\hline \multirow[t]{2}{*}{ BCAL3428 } & Ribonucleoside-diphosphate reductase & 1.58 & & protein & \\
\hline & beta chain & & BCAM1123 & ABC transporter ATP-binding protein & 1.52 \\
\hline BCAL3457 & Cell division protein FtsZ & 1.71 & BCAM1138 & Major facilitator superfamily protein & 1.77 \\
\hline \multirow[t]{2}{*}{ BCAM0010 } & 2-Amino-3-ketobutyrate coenzyme A & 2.03 & BCAM1140 & Putative aldehyde oxidase/xanthine & 1.52 \\
\hline & ligase & & BCAM1141 & Putative isochorismatase & 1.81 \\
\hline BCAM0032 & Conserved hypothetical protein & 1.71 & BCAM1147 & Isoquinoline 1-oxidoreductase alpha & 1.98 \\
\hline BCAM0064 & Conserved hypothetical protein & 1.89 & & subunit & \\
\hline BCAM0067 & Putative short-chain dehydrogenase & 2.24 & BCAM1164 & Conserved hypothetical protein & 1.87 \\
\hline BCAM0069 & Conserved hypothetical protein & 1.57 & BCAM1175 & Putative iron-sulfur cluster protein & 1.60 \\
\hline BCAM0070 & Putative hydrolase & 1.66 & BCAM1213 & Putative membrane protein & 2.19 \\
\hline BCAM0096 & ABC transporter ATP-binding protein & 2.32 & BCAM1255 & Putative exported protein & 1.88 \\
\hline BCAM0103 & Major facilitator superfamily protein & 1.65 & BCAM1265 & Putative amino acid permease & 1.80 \\
\hline BCAM0186 & Lectin & 2.64 & BCAM1316a & Conserved hypothetical protein & 2.00 \\
\hline \multirow[t]{2}{*}{ BCAM0188 } & $N$-acyl-homoserine lactone dependent & 1.57 & BCAM1316b & Conserved hypothetical protein & 1.54 \\
\hline & regulatory & & BCAM1335 & Glycosyltransferase & 1.52 \\
\hline BCAM0190 & Putative aminotransferase - class III & 2.44 & BCAM1358 & Gluconate 2-dehydrogenase & 1.52 \\
\hline BCAM0288 & response & & BCAM1443 & Putative exported protein & 2.64 \\
\hline BCAM0446 & Outer membrane efflux protein & 187.90 & BCAM1473 & Putative di-haem cytochrome $c$ & 1.67 \\
\hline BCAM0485 & Lacl family regulatory protein & 4.99 & & peroxidase & \\
\hline BCAM0487 & Conserved hypothetical & 1.53 & BCAM1491 & Putative exported protein & 1.56 \\
\hline BCAM0504 & CsbD-like protein & 2.24 & BCAM1572 & Methyl-accepting chemotaxis protein & 1.93 \\
\hline BCAM0505 & Putative membrane-attached protein & 1.67 & BCAM1573 & Alpha, alpha-trehalose-phosphate & 1.64 \\
\hline BCAM0507 & CsbD-like protein & 2.40 & & synthase & \\
\hline BCAM0521 & Putative IstB-like ATP-binding protein & 2.85 & BCAM1588 & Putative lyase & 1.74 \\
\hline BCAM0522 & Putative integrase & 1.76 & BCAM1602 & Conserved hypothetical protein & 1.59 \\
\hline BCAM0589 & Conserved hypothetical protein & 1.68 & BCAM1623 & Thiolase & 2.75 \\
\hline \multirow[t]{2}{*}{ BCAM0622 } & Two-component regulatory system, & 1.58 & BCAM1643 & AMP-binding protein & 1.76 \\
\hline & sensor kinase & & BCAM1704 & 2,3-Butanediol dehydrogenase & 1.79 \\
\hline BCAM0623 & $\begin{array}{l}\text { Two-component regulatory system, } \\
\text { response }\end{array}$ & 1.62 & BCAM1710 & $\begin{array}{l}\text { Putative enoyl-CoA } \\
\text { hydratase/isomerase }\end{array}$ & 1.58 \\
\hline BCAM0633 & Conserved hypothetical protein & 2.67 & BCAM1711 & Phenylacetate-coenzyme A ligase & 1.57 \\
\hline BCAM0634 & Hypothetical protein & 10.80 & BCAM1733 & Putative membrane protein & 2.36 \\
\hline BCAM0717 & Putative Gram-negative porin & 2.44 & BCAM1734 & Putative cytochrome $c$ & 1.73 \\
\hline BCAM0753 & Putative membrane protein & 2.18 & BCAM1735 & Putative oxidoreductase & 1.89 \\
\hline BCAM0780 & Putative helicase & 1.59 & BCAM1736 & Conserved hypothetical protein & 1.84 \\
\hline
\end{tabular}


Table A2 | Continued

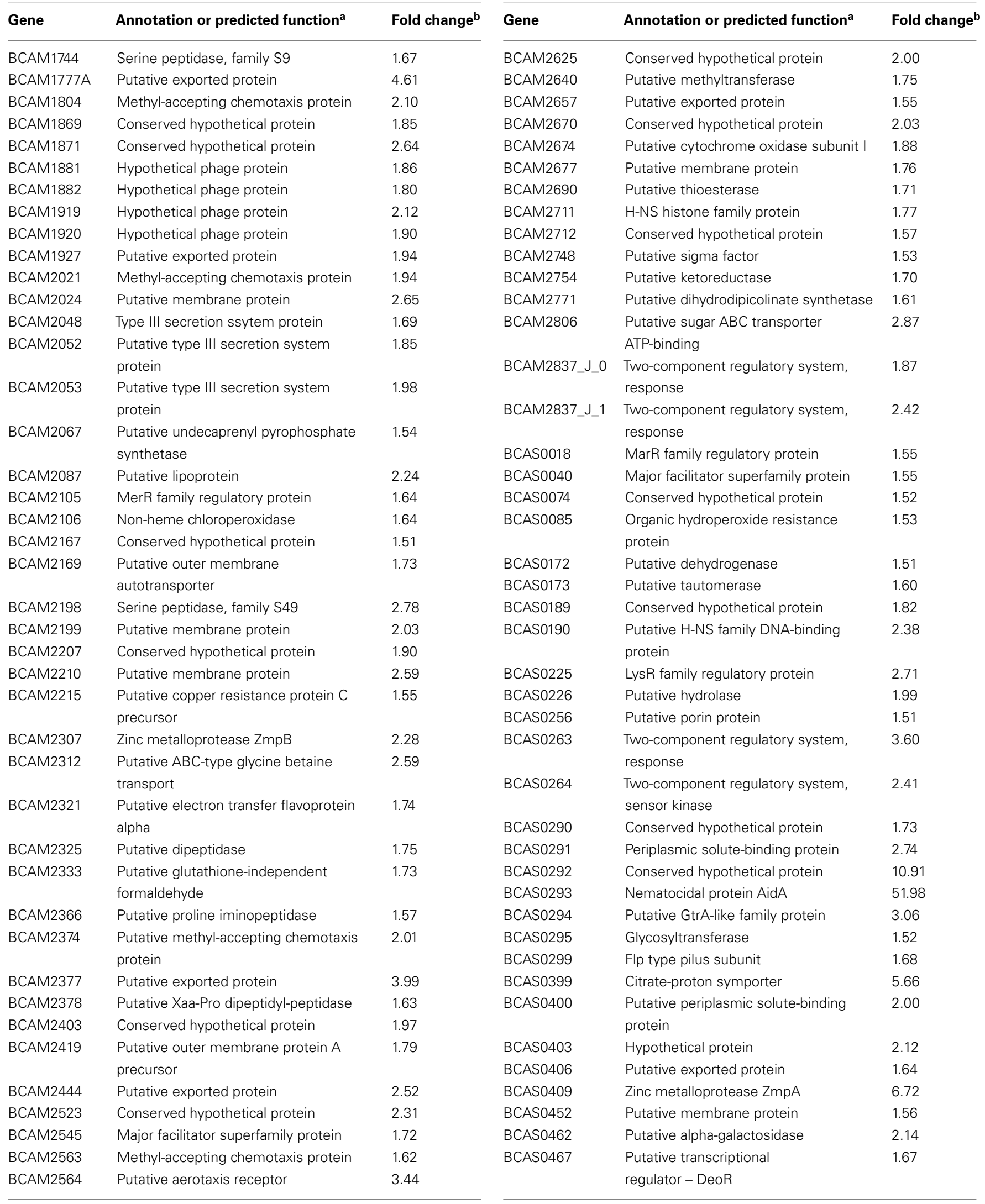


Table A2 | Continued

\begin{tabular}{lll}
\hline Gene & Annotation or predicted function & Fold change \\
\hline BCAS0481 & Putative lipoprotein & 1.86 \\
BCAS0510 & Hypothetical phage protein & 2.29 \\
BCAS0540 & Hypothetical phage protein & 1.72 \\
BCAS0548 & Hypothetical phage protein & 1.69 \\
BCAS0572 & Putative exported protein & 1.70 \\
BCAS0573 & Putative exported protein & 1.72 \\
BCAS0576 & Putative binding-protein-dependent & 1.52 \\
& transport & \\
BCAS0579 & Putative exported protein & 2.01 \\
BCAS0595 & Putative sugar efflux transporter & 1.53 \\
BCAS0596 & Conserved hypothetical protein & 1.58 \\
\hline
\end{tabular}

\begin{tabular}{lll}
\hline Gene & Annotation or predicted function & Fold change \\
\hline BCAS0661C & Hypothetical protein & 1.83 \\
BCAS0662 & Conserved hypothetical protein & 1.91 \\
BCAS0669 & Hypothetical protein & 1.90 \\
BCAS0700 & Putative oxygen-insensitive NAD(P)H & 1.52 \\
BCAS0717 & Hypothetical protein & 2.26 \\
BCAS0773 & Putative exported protein & 1.64 \\
pBCA055 & Putative membrane protein & 18.16
\end{tabular}

a Derived from B. cenocepacia J2315 (Holden et al., 2009) at http://Www. burkholderia.com Winsor et al., 2008) or http://www.microbesonline.org (Dehal et al., 2009).

${ }^{b}$ Fold change of RNA isolated from in vitro grown cultures relative to RNA recovered from rat lungs (in vivo) as determined by microarray analysis. 